\title{
Single-cell multimodal profiling of proteins and chromatin accessibility using PHAGE-ATAC
}

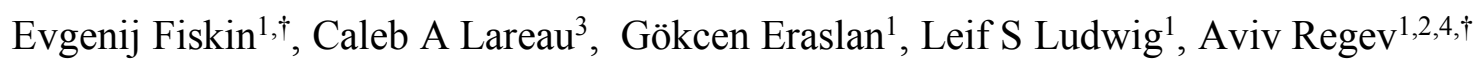

${ }^{1}$ Klarman Cell Observatory, Broad Institute of Harvard and MIT, Cambridge, MA, USA

${ }^{2}$ Howard Hughes Medical Institute, Department of Biology, Massachusetts Institute of Technology, Cambridge, MA, USA

${ }^{3}$ Departments of Genetics and Pathology, Stanford University, Stanford, CA, USA

${ }^{4}$ Current address: Genentech, 1 DNA Way, South San Francisco, CA, USA

† To whom correspondence should be addressed: efiskin@,broadinstitute.org (EF), aregev@,broadinstitute.org (AR) 


\section{Abstract}

2 Multi-modal measurements of single cell profiles are a powerful tool for characterizing cell states

3 and regulatory mechanisms. While current methods allow profiling of RNA along with either

4 chromatin or protein levels, connecting chromatin state to protein levels remains a barrier. Here,

5 we developed PHAGE-ATAC, a method that uses engineered camelid single-domain antibody

6 ('nanobody')-displaying phages for simultaneous single-cell measurement of surface proteins,

7 chromatin accessibility profiles, and mtDNA-based clonal tracing through a massively parallel

8 droplet-based assay of single-cell transposase-accessible chromatin with sequencing (ATAC-seq).

9 We demonstrate PHAGE-ATAC for multimodal analysis in primary human immune cells and for

10 sample multiplexing. Finally, we construct a synthetic high-complexity phage library for selection

11 of novel antigen-specific nanobodies that bind cells of particular molecular profiles, opening a new

12 avenue for protein detection, cell characterization and screening with single-cell genomics. 
15 Massively-parallel single-cell profiling has become an invaluable tool for the characterization of

16 cells by their transcriptome or epigenome, deciphering gene regulation mechanisms, and dissecting

17 cellular ecosystems in complex tissues (Klein et al., 2015; Lareau et al., 2019; Macosko et al.,

18 2015; Satpathy et al., 2019). In particular, recent advances have highlighted the power of

19 multimodal single-cell assays (Ma et al., 2020), such as cellular indexing of transcriptomes and

20 epitopes by sequencing (CITE-seq), that profile both transcriptome and proteins by DNA-barcoded

21 antibodies (Mimitou et al., 2019; Peterson et al., 2017; Stoeckius et al., 2017).

23 Although the vast combinatorial space of oligonucleotide barcodes theoretically allows parallel

24 quantification of an unrestricted number of epitopes, in practice, however, we are limited by the

25 availability of antigen-specific antibodies. Moreover, each antibody must be separately conjugated

26 with a unique oligonucleotide (oligo)-barcode, which currently does not allow a scalable and

27 pooled construction of barcoded antibody libraries. Finally, technologies for the combined high-

28 throughput measurement of the epigenome and proteome have not been described.

30 To overcome these limitations, we developed PHAGE-ATAC (Figures 1A-1C, Supp. Fig. 1), a

31 multimodal single-cell approach for phage-based multiplex protein measurements and chromatin

32 accessibility profiling using droplet-based scATAC-seq (10x Genomics scATAC (Satpathy et al.,

33 2019)). PHAGE-ATAC enables sensitive quantification of epigenome and proteins, captures

34 mtDNA that can be used as a native clonal tracer (Lareau et al., 2020; Ludwig et al., 2019),

35 introduces phages as renewable and cost-effective reagents for high-throughput single-cell epitope

36 profiling, and leverages phage libraries for the selection of antigen-specific antibodies 
37 (Hoogenboom, 2005; Smith, 1985), altogether providing a novel platform that greatly expands the

38 scope of the single-cell profiling toolbox.

40 Protein quantification in PHAGE-ATAC is based on epitope recognition by nanobody (Ingram et

41 al., 2018) (Nb)-displaying phages (Figure 1A, Supp. Fig. 1), in contrast to recognition by

42 oligonucleotide-conjugated antibodies in CITE-seq and related methods (Peterson et al., 2017;

43 Stoeckius et al., 2017), or fluorescently labeled antibodies in other techniques (Katzenelenbogen

44 et al., 2020; Paul et al., 2015). The hypervariable complementarity-determining region 3 (CDR3)

45 within each $\mathrm{Nb}$-encoding phagemid acts as a unique genetic barcode (Pollock et al., 2018) that is

46 identified by sequencing in PHAGE-ATAC and serves as a proxy for antigen detection and

47 quantification (Figure 1A, Supp. Fig. 1A). To allow phage-based epitope quantification alongside

48 accessible chromatin using droplet-based scATAC-seq, we engineered an M13 phagemid for the

49 in-frame expression of (1) an epitope-binding Nb, (2) a PHAGE-ATAC tag (PAC-tag) containing

50 the Illumina Read 1 sequence (RD1) and (3) the phage coat protein p3 for surface display (Figures

51 1A and 1B). This enables phage $\mathrm{Nb}(\mathrm{pNb})$-based recognition of cell surface antigens, simultaneous

52 droplet-based indexing of phagemids and ATAC fragments, as well as separate generation of

53 phage-derived tag (PDT) and ATAC sequencing libraries (Figure 1C, Supp. Fig. 2 and 3,

54 Methods).

56 We first confirmed that the PHAGE-ATAC modified phagemid workflow allows successful and

57 specific $\mathrm{pNb}$ antigen recognition and $\mathrm{pNb}$-based cell staining during scATAC cell lysis. As a first

58 proof-of-concept, we used HEK293T cells expressing surface-exposed glycosylphosphatidyl-

59 inositol (GPI)-anchored EGFP (EGFP-GPI) that are specifically recognized by an anti-EGFP pNb 
60 (Rothbauer et al., 2006) (Supp. Fig. 4A-4E). Importantly, introducing the PAC-tag did not impair

$61 \mathrm{Nb}$ display and antigen recognition (Supp. Fig. 4F and 4G). Moreover, fixation retained pNb-

62 based cell staining after the scATAC lysis step, with a standard scATAC-seq buffer (Supp. Fig.

63 5, Methods).

64

65 To benchmark PHAGE-ATAC for single cell profiling, we performed a 'species-mixing' 66 experiment, in which we pooled mouse (NIH3T3), human EGFP- (HEK293T) and human EGFP'

67 (HEK293T-EGFP-GPI) cells at a 2:1:1 ratio, followed by anti-EGFP pNb staining, library 68 generation and analysis using a custom computational workflow (Figure 1D and Supp. Fig. 6;

69 Methods). After filtering, we recovered 1,212 mouse and 1,158 human cell barcodes (Figure 1E),

70 with good library complexity, enrichment of fragments in peaks, and enrichment in transcription

71 start sites (Supp. Fig. 7A-7C), all comparable to gold-standard published reference data without

72 additional protein detection (Lareau et al., 2020; Satpathy et al., 2019). Analysis of EGFP PDT

73 counts confirmed the presence of $\mathrm{EGFP}^{+}$and EGFP- cells (Figures 1F and 1G) that together with

74 mouse cell barcodes were all recovered at expected input ratios (observed 2.09:1:1, expected

75 2:1:1), with no substantial differences in scATAC-seq data quality metrics (Figure 1H, Supp. Fig.

76 7). EGFP PDT levels by PHAGE-ATAC (Figures 1F and 1G) and EGFP fluorescence intensities

77 by standard flow cytometry (Figure 1I) were highly concordant (Figures 1J and 1K). Taken

78 together, these results established the use of PDTs for accurate and sensitive epitope quantification

79 in single cells concomitantly with scATAC-seq.

80

81 Next, we showed that PHAGE-ATAC can discern cellular states of primary peripheral blood

82 mononuclear cells (PBMCs) comparably to CITE-seq. For PHAGE-ATAC, we targeted well- 
83 characterized markers via a panel of three pNbs targeting CD4, CD8 and CD16 using previously

84 reported high-affinity $\mathrm{Nb}$ sequences (Roobrouck et al., 2016; Tavernier et al., 2017), as well as

85 anti-EGFP as a negative control (Methods). Flow cytometry of pNb-stained PBMCs and side-by-

86 side comparison between $\mathrm{pNb}$ and conventional antibody-stained cells confirmed the antigen-

87 specificity of the produced phages (Supp. Fig. 8). In addition, we further optimized the PHAGE-

88 ATAC lysis buffer to better preserve phage staining (Lareau et al., 2020) (Supp. Fig. 9; Methods).

89 Integrative canonical correlation analysis (Butler et al., 2018), clustering and dimensionality

90 reduction of PHAGE-ATAC data of 7,972 high-quality PBMCs and published CITE-seq data of

91 7,660 PBMCs (Stoeckius et al., 2017) (Figure 1L, Methods) identified the same set of expected

92 cell states and markers (Figure 1L and Supp. Fig. 10A). The distribution of PDTs and CITE-seq

93 antibody-derived tags (ADTs) across all cell types were highly correlated for each surface marker

94 (Figures 1M and 1N, Pearson's $r=0.69-0.94$ ). To further validate PDT partitioning independently

95 of CITE-seq, we determined differential gene activity scores from the PHAGE-ATAC data alone

96 by comparing scATAC profiles of T cells based on CD4 and CD8 PDT abundances (Supp. Fig.

97 10B and 10C). This identified both $C D 4$ and $C D 8$ loci as top hits and recovered many known

98 bona fide markers of $\mathrm{CD}^{+}$and $\mathrm{CD}^{+} \mathrm{T}$ cells (e.g. CD4: CTLA4, CD40LG, ANKRD55; CD8:

$99 P R F 1, E O M E S, R U N X 3$, Supp. Fig. 10C). Finally, EGFP PDTs were only detected at background

100 levels, confirming the high specificity of pNbs (Supp. Fig. 10D and 10E). These results illustrate

101 the capacity of PHAGE-ATAC to reliably and specifically detect endogenous cell surface proteins

102 in single cells along with their epigenomic profiles.

103

104 To scale PHAGE-ATAC, we next introduced a cost-effective alternative for sample multiplexing 105 in scATAC-seq using pNbs for Cell Hashing. A number of current methods allow 'overloading' 
antibody-tagged cells into droplets to increase single-cell processing throughput and mitigate batch

107 effects (Gehring et al., 2020; Lareau et al., 2019; McGinnis et al., 2019; Stoeckius et al., 2018).

108 To demonstrate hashtags for PHAGE-ATAC, we generated four anti-CD8 hashtag pNbs

109 (henceforth referred to as hashtags) by introducing different silent mutations into the anti-CD8

110 CDR3 (Figure 2A, Methods), allowing sequencing-based identification of the four hashtags. As

111 expected, the hashtags displayed comparable CD8 recognition within PBMCs (Supp. Fig. 11A).

112 To demonstrate phage-based hashing, we stained CD8 T cells from each of four healthy donors

113 with a unique hashtag, pooled them and processed the pool by PHAGE-ATAC, overloading 20,000

114 cells (Figure 2A) (vs. $\sim 6000$ cells without overloading). These yielded high-quality data for 8,366

115 cell barcodes, to which we assigned donor and singlet/doublet status from hashtag counts

116 (Methods), identifying the sample of origin for 6,438 singlets and 703 doublets (observed doublet

117 rate $8.4 \%$ compared to $10 \%$ expected) (Figure $2 \mathbf{B}$ ). As expected, barcodes assigned to an

118 individual hashtag had higher count distributions for the respective hashtag (Figure 2C). Singlet

119 and doublet assignments were concordant with a two-dimensional embedding of hashtag count

120 data (Figure 2D), with the expected higher numbers of chromatin fragments and hashtag counts

121 in doublets $\left(\mathrm{p}<2.2 \times 10^{-16}\right.$; Mann-Whitney test, Figures $2 \mathbf{E}$ and 2 F). The hashtag-based

122 assignments were also highly concordant with assignments based on computationally derived

123 donor genotypes from accessible chromatin profiles (Heaton et al., 2020) (Methods), with a singlet

124 classification accuracy of $99.3 \%$ and an overall classification accuracy of $92.9 \%$ (Figure 2G).

125 Interestingly, chromatin accessibility analyses revealed a small set of putative B cells (Supp. Fig.

126 11B and 11C), consistent with the presence of a minor contaminating population after CD8 T cell

127 enrichment. While B cells were classified as hashtag-negative, genotype and hashtag-based 
128 classification were highly consistent across CD8 T cell states (Figure 2H and Supp. Fig. 11D-

129 11F), confirming hashtag antigen specificity.

131 PHAGE-ATAC also enables the concomitant capture of mitochondrial genotypes via

132 mitochondrial DNA-derived Tn5 fragments (Lareau et al., 2020), providing a third data modality

133 that relates protein and accessible chromatin profiles to cell clones. Mitochondrial genotyping

134 using mgatk (Lareau et al., 2020) was broadly concordant with the hashtag assignments, but

135 showed that two donors (PH-B and PH-C) had indistinguishable mitochondrial haplotypes,

136 whereas each of the other two donors had several distinguishing mitochondrial variants (Supp.

137 Fig. 11G). Collectively, these results established the use of hashtag $\mathrm{pNbs}$ for sample multiplexing

138 in scATAC-seq, and its ability to capture mtDNA for clonal analysis.

140 The production of novel high-quality antigen-specific antibodies is laborious, expensive and

141 limited by animal immunization, generating a bottleneck for antibody-based protein profiling. In

142 contrast, recombinant antibody technology based on phage display has allowed fast and cost-

143 effective selection of high-affinity binders (Miersch and Sidhu, 2012). To enable rapid generation

144 of novel antigen-specific pNbs for PHAGE-ATAC, we developed PHAGE-ATAC Nanobody

145 Library (PANL), a synthetic high-complexity $\left(4.96 \times 10^{9}\right)$ pNb library (Supp. Fig. 12). To

146 demonstrate identification of novel pNbs using PANL, we performed a selection against EGFP-

147 GPI-expressing HEK293T cells, while counter-selecting using parental HEK293T (Figure 2I).

148 Over three selection rounds, we monitored the enrichment of pNbs by staining EGFP-GPI ${ }^{+}$cells,

149 revealing a steady increase of antigen-recognizing pNbs with each additional round (Figure 2J).

150 Screening of 94 clones after the final (third) selection demonstrated that at least $95 \%$ of clones 
151 recognized EGFP-GPI ${ }^{+}$cells with strong binding (Q2/Q1 >1) (Figure 2K and Supp. Fig. 13). As

152 clones varied in their ability to bind EGFP-GPI ${ }^{+}$cells, we picked 7 clones ( 5 strong and 2 weak

153 binders) and sequenced their phagemid inserts. Sanger sequencing uncovered the presence of

154 multiple identical clones (A2 and C1, B8 and E3, Figure 2L), illustrating selection-driven

155 convergence. Finally, side-by-side comparison of a selected clone (C5) and a reported high-affinity

156 anti-EGFP Nb derived from immunized animals (Rothbauer et al., 2006) indicated similar binding

157 to EGFP-GPI ${ }^{+}$cells (Figure $2 \mathbf{M}$ ). These results demonstrate the utility of PANL for the rapid

158 selection of pNbs to detect and quantify antigens of interest on cells. They further illustrate

159 PANL's potential for the generation of a new toolbox of barcoded affinity reagents for single cell

160 genomics.

161

162 In conclusion, PHAGE-ATAC uses the power of recombinant phage display technology as the

163 basis for single cell profiling of cell surface proteins, chromatin accessibility and mtDNA. This

164 allows users to leverage the renewable nature, low cost and scalability of pooled phage library

165 preparation as well as the compact size and stability of nanobodies (Ingram et al., 2018). We

166 envisage PHAGE-ATAC as an adaptive tool that may be further combined with unique molecular

167 identifiers for phagemid counting and other engineerable scaffolds used in phage display

168 applications (e.g. scFv, Fab) (Gebauer and Skerra, 2009). In the future, we believe this will

169 significantly enhance our ability for the cost-effective (Supp. Fig. 14), multimodal single-cell

170 characterization of the proteome, epigenome and likely additional readouts at an unprecedented

171 depth and specificity.

172

173 


\section{Figure legends}

\section{Figure 1. PHAGE-ATAC for massively-parallel simultaneous measurement of protein}

176 epitopes and chromatin accessibility

177 (A)-(C) PHAGE-ATAC overview. (A) Schematic of engineered nanobody-displaying M13

178 phages used for PHAGE-ATAC. Nanobodies are displayed via fusion to p3, the PAC-tag is placed

179 in the linker between nanobody and p3. M13 phagemids contain a pelB leader for periplasmic

180 secretion and incorporation of fusions during phage assembly. (B) PAC-tag RD1 sequence (pink)

181 allows capture by 10x ATAC gel bead oligos (Supp. Fig. 2A), without interrupting translation

182 (right). (C) PHAGE-ATAC workflow. After phage nanobody staining, fixation, lysis and

183 tagmentation in bulk (leftmost), single cells and 10x ATAC gel beads are encapsulated into

184 droplets using 10x microfluidics, followed by linear amplification with simultaneous droplet

185 barcoding of chromatin fragments and phagemids via hybridization of 10x barcoding primers to

186 RD1 sequences (second from left). Separate PDT and ATAC sequencing libraries are prepared

187 (second from right and Supp. Fig. 3). Right: Representative BioAnalyzer traces. BC, bead

188 barcode. (D)-(K) Single-cell ATAC and EGFP specificity in a species-mixing experiment. (D)

189 Experimental scheme. (E) Number of human (x axis) and mouse (y axis) ATAC fragments

190 associated with each bead barcode (dots), colored by assignment as human EGFP+ (light blue),

191 human EGFP- (dark blue), mouse (red), doublet (purple, >10\% human and mouse fragments). (F)

192 EGFP PDT counts (y axis, $\log _{10}$ scale) and number of ATAC fragments (x axis, $\log _{10}$ scale) for

193 each bead barcode (dots) colored as in E (color legend). (G),(H) Distributions of EGFP PDTs (G,

$194 \mathrm{y}$ axis, $\log _{10}$ scale) and ATAC fragments (H, y axis, $\log _{10}$ scale) in each of the three populations

195 (x axis) (Mann-Whitney one-tailed, $* * * \mathrm{p}<10^{-4}$, NS=not significant). Line: median. (I)-(K) PDT

196 quantification is consistent with flow cytometry. EGFP fluorescence (I, y axis) and distribution (J, 
$197 \mathrm{x}$ axis) and distribution of EGFP PDT (K, x axis) in EGFP+ (light blue) and EGFP- (dark blue)

198 human cells. (L)-(N) PHAGE-ATAC and CITE-seq compare well in human PBMCs. (L),(M)

199 Two-dimensional joint embedding of scRNA-seq profiles from PBMCs from published CITE-seq

200 (Stoeckius et al., 2017) and of scATAC-seq profiles from PBMCs generated by PHAGE-ATAC,

201 colored by annotated cell types (L) or by the level of protein marker ADTs (M, top) or PDTs (M,

202 bottom). (N) Agreement between protein level estimates from CITE-seq and PHAGE-ATAC.

203 ADT (y axis, centered log ratio (CLR)) and PDT (x axis, CLR) for each marker gene across cell

204 types (dots, colored as in L), Pearson's $r$ is shown.

205 
Figure 2. PHAGE-ATAC compatible phage nanobodies enable sample multiplexing and can phage hashtags and a subsequent hashing experiment using CD8 T cells from four human donors.

211 hashtag (rows) across cells (columns) sorted by their HTODemux classification (Phage hash ID).

212 (C) PDT count distributions for each hashtag (colored histograms) across the four Phage hash IDs

213 (Wilcoxon two-tailed, $* * * \mathrm{p}<10^{-4}$ ). (D) Two-dimensional embedding of cell barcodes by PDT 214 count data, colored by PDT count for the marked hashtag (4 left panels) or by singlet/doublet 215 classification (right). (E),(F) Distribution of the number of ATAC fragments per barcode (E, y 216 axis) or PDT counts (F, y axis) in cell barcodes in each category (x axis) (Mann-Whitney two217 tailed, $* * * \mathrm{p}<10^{-4}, \mathrm{NS}=$ not significant). Line: median. (G) Number and percent (color) of barcodes 218 shared between each genotype-based (Genotype ID, rows) and Phage hashtag ID-based (columns) 219 assignments. Top: overall accuracy. (H) Proportion of cells of each type (y axis) within each 220 assigned barcode category ( $\mathrm{x}$ axis) based on either genotype (left) or and hashtags (right), and in

221 the negative fraction (far right). (I)-(M), Selection of PHAGE-ATAC nanobodies by phage

222 display. (I) Schematic of phage display selection using PANL (Methods). PANL is panned against

223 EGFP-expressing cells (HEK293T-EGFP-GPI) with preceding counter-selection against antigen-

224 devoid parental cells (HEK293T). Bound phages are eluted, used to infect bacterial hosts and 225 output libraries are generated. After multiple selection rounds, antigen-recognizing phage 226 nanobody clones are picked, phagemids are isolated and nanobody inserts are sequenced. (J) Flow 227 cytometry analysis of selection progress. Flow cytometry plots of EGFP fluorescence (y axis) and 228 phage binding (x axis, AlexaFluor647 area) to EGFP-GPI-expressing HEK293T cells (EGFPhi and 
$229 \mathrm{EGFP}^{\mathrm{lo}}$ ) in, from left, the input library and after each of three consecutive selection cycles (see

230 also Supp. Fig. 4C and Methods). (K) Flow cytometry screen of 94 phage nanobody clones

231 derived from selection round 3. Ratio of Q2 to Q1 signal (as defined in Figure 1J) when staining

232 EGFP-GPI-expressing HEK293T (EGFPhi and EGFPlo ) cells with individual phage nanobodies

233 after the $3^{\text {rd }}$ round of selection. Dashed line: threshold of Q2/Q1=1 used for calling positive clones.

234 (L) CDR sequences and CDR3 length of selected clones obtained by Sanger sequencing. * non-

235 randomized constant positions in PANL library (see also Supp. Fig. 12A). (M) Flow cytometry

236 plots of EGFP fluorescence (y axis) and phage binding ( $\mathrm{x}$ axis, AlexaFluor647 area) to EGFP-

237 GPI-expressing HEK293T cells (EGFPhi and EGFPlo $)$ using an immunization-based (Rothbauer et

238 al., 2006) anti-EGFP Nb-displaying phage (middle), clone C5 from our screen (right) and an anti-

239 mCherry phage negative control (left). 


\section{Supplementary Figure legends}

\section{Supplementary Figure 1: Barcoding strategies for epitope quantification by PHAGE-ATAC}

\section{4 vs. CITE-seq}

245 (A) Nanobody-displaying phages for PHAGE-ATAC. The phagemid contained within a particular

246 phage particle encodes the protein displayed on that same phage, and PHAGE-ATAC leverages

247 the hypervariable nanobody CDR3 sequences as unique genetic barcode identifiers for each phage.

248 (B) Oligonucleotide-conjugated antibodies for CITE-seq. Each antibody is separately conjugated

249 with a unique DNA-barcode.

250

251 


\section{Supplementary Figure 2. Phage barcode amplification using 10x Genomics scATAC-seq}

\section{3 primers enabled by a modified Illumina Read 1 (RD1) sequence}

254 (A) Schematic of gel bead oligos showing Illumina P5 sequence (P5), random bead barcode (BC)

255 and the first 14bp of RD1 used for hybridization with RD1-containing chromatin fragments and

256 engineered PHAGE-ATAC phagemids. (B) Nanobody-encoding phagemid constructs for RD1-

257 mediated CDR3 barcode capture by 10x Genomics primers. The top strand is the coding strand.

258 Orientation (arrows and shaded boxes), nucleotide sequence and translation product of RD1-

259 containing constructs are shown. To avoid generating a stop codon by introduction of RD1 into

260 the nanobody-p3 reading frame additional codons are introduced to maintain the reading frame

261 across RD1, thus establishing the PAC tag. (C) Agarose gel after two-step PCR consisting of linear

262 amplification using the 10x ATAC primer followed by exponential PCR using P5 and Illumina

263 Read 2 (RD2)-containing nanobody-specific primers. PDTs were only obtained for PAC-tagged

264 phagemids with RD1 located on the non-coding strand (3'-5' orientation relative to nanobody).

265 Abbreviations as in A. Control PCR was performed using two primers hybridizing within the

266 nanobody sequence (Methods). 


\section{Supplementary Figure 3. Workflow for separate preparation of scATAC and PDT libraries}

\section{0 after droplet-based indexing}

271 Schematic of post barcoding steps for the generation of ATAC and PDT sequencing libraries

272 (Methods). After breaking emulsions, barcoded linear amplification products are purified and

273 samples are split. ATAC fragment libraries are immediately processed for sample index PCR. PDT

274 libraries are first amplified in a PDT-specific PCR using a CDR3 flanking constant nanobody

275 sequence as PCR handle. PDT amplification allows RD2 adapter introduction required for final

276 sample indexing. P5 and P7, Illumina P5 and P7 sequences. CBC, random 10x bead cell barcode.

277 i7, sample index.

278

279 


\section{Supplementary Figure 4. Detection of membrane-localized EGFP via anti-EGFP nanobody-}

\section{1 displaying phages}

282 (A),(B) Membrane expressed EGFP. (A) Microscopy images of HEK293T cells expressing

283 indicated constructs, showing differential localization of untagged cytosolic EGFP (pCAG-EGFP,

284 middle) and GPI-anchored membrane-localized EGFP (pCAG-EGFP-GPI, right, Methods). (B)

285 Schematic of surface-exposed GPI-anchored EGFP. (C) Schematic for detection of phage

286 recognition via flow cytometry. Phage-stained cells are incubated with mouse anti-M13 coat

287 protein antibodies followed by detection by Alexa Fluor 647-conjugated anti-mouse secondary

288 antibodies. Phage binding is thus reflected by Alexa Fluor 647 signal. (D) Flow cytometry analysis

289 of anti-EGFP phage nanobody binding to EGFP-expressing HEK293T cells. EGFP fluorescence

290 (y axis) and phage binding (x axis, Alexa Fluor 647) in each of the HEK293T cell populations as

291 in A, either unstained (left) or stained with an anti-EGFP phage (right). EGFP-expressing cells

292 were always characterized by the presence of both EGFPhi and EGFPlo populations. (E) Specificity

293 of detection. As in D but using the indicated staining controls for specific staining of membrane-

294 EGFP-expressing cells. (F),(G) PAC-tag does not impact nanobody display and antigen

295 interaction. EGFP fluorescence (F, y axis) and phage binding (F, x axis, Alexa Fluor 647) and

296 distribution of level of phage binding (G) for phage-stained EGFP-GPI expressing cells using

297 indicated phage nanobodies (for RD1 sequences see Supp. Fig. 2B). 
300 Supplementary Figure 5. Optimization of fixation and lysis conditions for PHAGE-ATAC

\section{1 species-mixing experiment}

302 EGFP fluorescence (A, y axis) and phage binding (A, x axis, Alexa Fluor 647) and distribution of

303 level of phage binding (B) for EGFP-GPI expressing cells stained with PAC-tagged anti-EGFP-

$304 \mathrm{Nb}$ displaying phages after fixation and permeabilization using indicated conditions.

305

306 


\section{Supplementary Figure 6. Computational workflow for PHAGE-ATAC data analysis}

308 Paired-end sequencing output is demultiplexed using sample index information (left) to recover

309 ATAC and PDT fastqs. ATAC fastqs are processed using CellRanger-ATAC count for fragment

310 alignment, assignment of cell barcodes and generation of peak-cell barcode matrices. CDR3

311 barcode sequences are used to search PDT_R3 fastqs and identify CDR3-containing sequencing

312 clusters. Matching of cluster identifiers is used to derive corresponding cell barcodes from

313 PDT_R2 fastqs. Recovered PDT cell barcode lists are filtered using cell barcodes called by

314 CellRanger. Cell barcode occurrences are counted to generate PDT-cell barcode count matrices

\section{5 (Methods).}


318 Supplementary Data Figure 7. PHAGE-ATAC quality metrics for human-mouse species-

\section{9 mixing experiment}

320 (A) Fraction (y axis) and number (x axis, $\log _{10}$ scale) of unique chromatin fragments overlapping

321 peaks for each barcode (dot) colored by populations (color legend). (B),(C) Distribution of fraction

322 of unique ATAC fragments overlapping peaks (B, y axis) or TSS (C, y axis) in each of the three

323 cell populations ( $\mathrm{x}$ axis) (Mann-Whitney two-tailed, $* * * \mathrm{p}<10^{-4}$, NS=not significant). Line:

324 median. 
327 Supplementary Figure 8. Validation of PAC-tagged anti-CD4, anti-CD8 and anti-CD16

328 nanobody-displaying phages

329 (A) Flow cytometry gating strategy for analyzed phage-stained PBMCs. (B) Flow cytometry-based

330 binding assessment of indicated surface marker-recognizing phage nanobodies to gated

331 lymphocyte and monocyte populations, anti-EGFP pNb was used as negative control. (C)

332 Comparison of PBMCs stained with a well-characterized anti-CD4 antibody or generated anti-

333 CD4 phage nanobody. Phage binding is reflected by Alexa Fluor 647 fluorescent signal intensity. 
336 Supplementary Figure 9. Optimization of fixation and lysis conditions for PHAGE-ATAC

\section{7 using PBMCs}

338 (A) Binding of generated anti-CD4 phage nanobodies to PBMCs under indicated conditions. Two

339 different formaldehyde concentrations as well as various depicted lysis buffers were used. Phage

340 binding is reflected by Alexa Fluor 647 fluorescent signal intensity. (B) Histogram of data in (A). 


\section{Supplementary Figure 10. Multimodal single-cell analysis of human PBMCs using PHAGE-}

\section{ATAC}

345 (A) Two-dimensional joint embedding of scRNA-seq profiles from PBMCs from published CITE-

346 seq (Stoeckius et al., 2017) and of scATAC-seq profiles from PBMCs generated by PHAGE-

347 ATAC, colored by the measured RNA level from CITE-Seq (top panels) or by gene activity scores

348 from PHAGE-ATAC (bottom panels) (Methods). (B),(C) PHAGE-ATAC gating by phage 349 staining highlights cell type specific loci. (B) PDT count-based classification of CD4 ${ }^{+}$and CD $^{+}$

350 T cells. PDT counts (CLR transformed) of CD8 (y axis) and CD4 (x axis) in each cell (dots). Red 351 boxes: gates for CD4+ and CD8+ cells. (C) Average fold change ( $\mathrm{x}$ axis, $\left.\log _{2}\right)$ and associated

352 significance (y axis, $-\log _{10}(\mathrm{P}$-value) for each gene activity comparing between PDT-classified CD4

353 and CD8 T cells shown in B. Known bona fide markers of either CD4 or CD8 T cells are marked.

354 (D) Negative control. Embedding of PHAGE-ATAC data as in A, colored by anti-EGFP pNb PDT.

355 (E) Distribution of phage counts (y axis, $\log _{10}$ ) for each cell barcode for each assayed nanobody 356 (x axis). 


\section{Supplementary Figure 11. Sample multiplexing using hashtag phages}

360 (A) Validation of phage hashtag binding. Flow cytometry of anti-CD8 hashtag phages bound

361 (Alexa Fluor 647 fluorescent signal, x axis) to lymphocytes gated via flow cytometry of phage-

362 stained PBMCs (as shown in Supp. Fig. 8A). (B) Cell type identification. Two-dimensional

363 embedding of hashed CD8 T cells analyzed by PHAGE-ATAC, colored by cell type annotation.

364 (C) Pseudobulk chromatin accessibility track plots for $C D 8, C D 3$ and $M S 4 A 1(C D 20)$ loci across

365 identified cell types. (D) Embedding as in B with cells colored by CD8 hashtag PDTs. (E),(F)

366 Distribution of maximal CD8 PDT density (E, y axis) or unique chromatin fragments (F, y axis)

367 for each cell barcode in $\mathrm{CD}^{-}$(B cell 1 and B cell 2 ) and $\mathrm{CD}^{+}$(non-B cell) cells (x axis) (Mann-

368 Whitney two-tailed, $* * * p<10^{-4}$ ). (G) Concordance between hashtag-based classification of

369 barcodes and identified mtDNA SNPs. Heteroplasmy (allele frequency percentage; color bar) of

370 different mtDNA variants (rows) in each cell (column), labeled by hashtag assignment (vertical

371 top color bar).

372

373 


\section{Supplementary Figure 12. Establishment of PANL, a fully synthetic high-complexity PAC-}

\section{5 tagged phage nanobody library}

376 (A) Schematic of PANL library design and library phagemid. CDR3 sequence diversification and

377 nanobody framework (grey) in PANL are based on a previously reported nanobody randomization

378 strategy (McMahon et al., 2018). White box: expected frequency of amino acids at each

379 hypervariable position (denoted by X), adjusted by using a custom randomized primer mix for

380 library generation (Methods). CDR3 loops contained either 7, 11 or 15 hypervariable positions,

381 resulting in total CDR3 lengths of 10 (short), 14 (medium) or 18 (long) amino acids. Partially

382 randomized positions are depicted as columns, constant positions contain a single amino acid. A

383 deposited structure of anti-EGFP Nb (PDB: 3ogo (Kubala et al., 2010)) with colored CDR3 loops

384 is shown. PANL phagemid is analogous to the one shown in Figure 1A. (B) Expected (grey) and

385 observed (red) frequencies (x axis) of amino acids at hypervariable positions (y axis) (Methods).

386 (C) Amplification products of phagemid insert-spanning PCR reactions using depicted primers for 38725 randomly picked PANL clones. Product sizes due to presence of long, medium or short CDR3

388 are shown. (D) CDR3 sequences of selected clones from C obtained by Sanger sequencing, CDR3

389 length is indicated, * non-randomized constant positions in the PANL library. 


\section{Supplementary Figure 13. Flow cytometry-based screen of nanobody-displaying phage}

\section{3 clones from selection round 3}

394 Flow cytometry analysis of round 3 phage nanobody clones for binding to EGFP-GPI expressing

395 cells (EGFPhi and EGFP ${ }^{\text {lo }}$ populations can be observed) with either strong (A) or weaker (B)

396 binders. Phage nanobodies against mCherry were used as negative control. Phage binding is

397 reflected by Alexa Fluor 647 signal. 
bioRxiv preprint doi: https://doi.org/10.1101/2020.10.01.322420; this version posted October 2, 2020. The copyright holder for this preprint (which was not certified by peer review) is the author/funder, who has granted bioRxiv a license to display the preprint in perpetuity. It is made available under aCC-BY-NC-ND 4.0 International license.

\section{Supplementary Figure 14. Estimates of cost per reaction for phage nanobodies}

401 Comparison of cost estimates per reaction step and overall for a phage nanobody produced

402 recombinantly.

403

404 
Methods

406

407

408

409

410

411

412

413

414

415

416

417

418

419

420

421

422

423

424

425

426

427

\section{Cloning of phagemids for display of PAC-tagged nanobody-p3 fusions for PHAGE-ATAC}

Based on the 10x scATAC bead oligo design (Supp. Fig. 2A), we hypothesized that introduction of an RD1 flanking the $\mathrm{Nb} \mathrm{CDR} 3$ barcode would enable barcode capture alongside accessible chromatin fragments during droplet-based indexing. To avoid premature termination of nanobodyp3 fusion translation due to the introduction of RD1, we modified the RD1-spanning reading frame, which resulted in the expression of a 12-amino acid PHAGE-ATAC tag (PAC-tag). To generate a phagemid for C-terminal fusion of both PAC-tag and p3, 20ng pDXinit (Addgene ID: 110101) were subjected to site-directed mutagenesis with primers EF77 and EF78 using PfuUltraII (Agilent) in $50 \mu \mathrm{l}$ reactions. PCR conditions were $95^{\circ} \mathrm{C} 3 \mathrm{~min} ; 19$ cycles $95^{\circ} \mathrm{C} 30 \mathrm{sec}, 60^{\circ} \mathrm{C} 1 \mathrm{~min}$, $68^{\circ} 12 \mathrm{~min}$; final extension $72^{\circ} \mathrm{C} 14 \mathrm{~min}$. Template DNA was digested for $1.5 \mathrm{~h}$ at $37^{\circ} \mathrm{C}$ by addition of $1.5 \mu \mathrm{l}$ DpnI (Fastdigest, Thermo Scientific). PCR reactions were then purified using GeneJet Gel Extraction Kit (Thermo Scientific) and eluted in $45 \mu 1$ water. $20 \mu 1$ eluate were transformed into chemically-competent E. coli (NEB Stable Competent) and plated on LB-Ampicillin, yielding pDXinit-PAC. For cloning of nanobody-PAC-p3 fusion-encoding phagemids, nanobody sequences (Supplementary Table 3) were ordered as gBlocks from IDT. 25ng nanobody gBlocks were first amplified by PCR to introduce SapI restriction sites. Primers EF87 and EF88 were used for CD4 Nb, primers EF87 and EF89 for CD16 Nb and primers EF104 and EF105 for CD8 Nb. $50 \mu 1 \mathrm{PCR}$ reactions using Q5 (NEB) were cycled $98^{\circ} \mathrm{C} 1 \mathrm{~min} ; 35$ cycles $98^{\circ} \mathrm{C} 15 \mathrm{sec}, 60^{\circ} \mathrm{C} 30 \mathrm{sec}$, 
$42872^{\circ} 30 \mathrm{sec}$; final extension $72^{\circ} \mathrm{C} 3 \mathrm{~min}$. PCR reactions were loaded on a $1 \%$ agarose gel, expected

429 bands were cut and PCR products were extracted using GeneJet Gel Extraction Kit (Thermo

430 Scientific) and eluted in $40 \mu$ water. Cloning was performed using the FX system as described

431 previously (Geertsma and Dutzler, 2011). Briefly, each eluted insert was mixed with 50ng

432 pDXinit-PAC in a molar ratio of 1:5 (vector:insert) in $10 \mu 1$ reactions and digested with $0.5 \mu 1$ SapI

433 (NEB) for $1 \mathrm{~h}$ at $37^{\circ} \mathrm{C}$. Reactions were incubated for $20 \mathrm{~min}$ at $65^{\circ} \mathrm{C}$ to heat-inactivate SapI, cooled

434 down to room temperature and constructs were ligated by addition of $1.1 \mu 110 \mathrm{x}$ T4 ligase buffer

435 (NEB) and $0.25 \mu 1 \mathrm{~T} 4$ ligase (NEB) and incubation for $1 \mathrm{~h}$ at $25^{\circ} \mathrm{C}$. Ligation was stopped by heat-

436 inactivation for $20 \mathrm{~min}$ at $65^{\circ} \mathrm{C}$ followed by cooling to room temperature. $2 \mu 1$ ligation reactions

437 were transformed into chemically-competent E. coli (NEB Stable Competent) and plated on 5\%

438 sucrose-containing LB-Ampicillin, yielding pDXinit-CD4Nb-PAC, pDXinit-CD8Nb-PAC and

439 pDXinit-CD16Nb-PAC. For cloning of CD8 hashtag phagemids, 20ng pDXinit-CD8Nb-PAC

440 were used as template for site-directed mutagenesis (as described earlier in this section) using

441 primers EF156 and EF157 to generate pDXinit-CD8Nb(PH-A)-PAC, primers EF158 and EF159

442 for pDXinit-CD8Nb(PH-B)-PAC, primers EF164 and EF165 for pDXinit-CD8Nb(PH-C)-PAC

443 and primers EF166 and EF167 for pDXinit-CD8Nb(PH-D)-PAC. For cloning of EGFP Nb-

444 displaying phagemids, the EGFP Nb sequence from pOPINE GFP nanobody (Addgene ID: 49172)

445 was amplified in 50 $\mu 1$ PCR reactions with Q5 (NEB) using 25ng plasmid template and EF05 and

446 EF06 primers. The EGFP nanobody insert was cloned into pDXinit using FX cloning (described

447 earlier), yielding pDXinit-EGFPNb. EGFP Nb-displaying phagemids containing RD1 in different

448 orientations were cloned by using pDXinit-EGFPNb and performing site-directed mutagenesis

449 (described earlier) with EF73 and EF74 to obtain pDXinit-EGFPNb-PAC or using EF75 and EF76

450 yielding pDXinit-EGFPNb-RD1(5-3). For introduction of a PCR handle required for PDT library 
451 amplification, pDXinit-EGFPNb-PAC was subjected to site-directed mutagenesis (as described

452 earlier in this section) using primers EF78 and EF79, yielding pDXinit-EGFPNb(handle)-PAC.

453 For cloning of mCherry $\mathrm{Nb}$-displaying phagemids, the mCherry $\mathrm{Nb}$ sequence from $\mathrm{pGex6 \textrm {P } 1}$

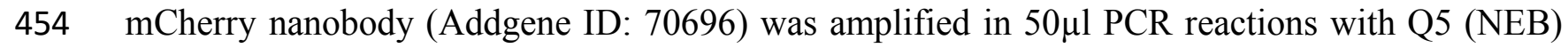

455 using 25ng plasmid template and EF07 and EF08 primers. The mCherry nanobody insert was

456 cloned into pDXinit using FX cloning (as described earlier in this section), yielding pDXinit-

457 mCherryNb. All constructs are listed in Supplementary Table 2.

458

\section{Analysis of RD1-mediated phagemid amplification using RD1-containing primers}

$4605 \mathrm{ng}$ of either pDXinit-EGFPNb, pDXinit-EGFPNb-PAC or pDXinit-EGFPNb-RD1(5-3) were

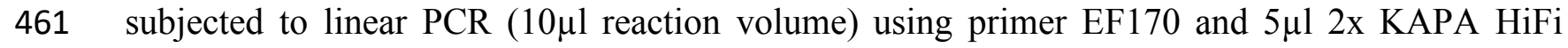

462 HotStart ReadyMix (Roche) and cycling conditions $98^{\circ} \mathrm{C} 2 \mathrm{~min} ; 12$ cycles $98^{\circ} \mathrm{C} 10 \mathrm{sec}, 59^{\circ} \mathrm{C} 30 \mathrm{sec}$,

$46372^{\circ} \mathrm{C} 1 \mathrm{~min}$; final extension $72^{\circ} \mathrm{C} 5^{\circ} \mathrm{min}$. After completion, $0.625 \mu 1$ of each primer EF147 and

464 EF57, $1.25 \mu 1$ water and $12.5 \mu 12 x$ KAPA were added. Nb-specific PCR was performed using $98^{\circ} \mathrm{C}$

$4653 \mathrm{~min} ; 30$ cycles $98^{\circ} \mathrm{C} 15 \mathrm{sec}, 65^{\circ} \mathrm{C} 20 \mathrm{sec}, 72^{\circ} \mathrm{C} 1 \mathrm{~min}$; final extension $72^{\circ} \mathrm{C} 5 \mathrm{~min}$. PCR using

466 primers EF57 and EF58 and indicated plasmid templates was used as amplification control.

\section{Phage production}

469 Phagemid-containing SS320 (Lucigen) cultures were incubated overnight in 2YT medium 470 containing $2 \%$ glucose, $50 \mu \mathrm{g} / \mathrm{ml}$ Ampicillin and $10 \mu \mathrm{g} / \mathrm{ml}$ Tetracycline $(2 \mathrm{YT} / 2 \% / \mathrm{A} / \mathrm{T})$ at $37^{\circ} \mathrm{C}$,

471 240rpm. Cultures were diluted 1:50 in $2 \mathrm{YT} / 2 \% / \mathrm{A} / \mathrm{T}$ and grown for $2-3 \mathrm{~h}$ at $37^{\circ} \mathrm{C}, 240 \mathrm{rpm}$ until

472 OD600 $=0.4-0.5 .5 \mathrm{ml}$ bacteria were then infected with $200 \mu 1 \mathrm{M} 13 \mathrm{~K} 07$ helper phage (NEB) and

473 incubated for $60 \mathrm{~min}$ at $37^{\circ} \mathrm{C}$. Bacteria were collected by centrifugation and resuspended in $50 \mathrm{ml}$ 
4742 YT containing $50 \mu \mathrm{g} / \mathrm{ml}$ Ampicillin and $25 \mu \mathrm{g} / \mathrm{ml} \mathrm{Kanamycin} \mathrm{(2YT/A/K).} \mathrm{Phages} \mathrm{were} \mathrm{produced}$

475 overnight by incubation at $37^{\circ} \mathrm{C}, 240 \mathrm{rpm}$. Cultures were centrifuged and phages were precipitated

476 from supernatants by addition of $1 / 4$ th volume $20 \%$ PEG-6000/2.5M NaCl solution and incubation

477 on ice for $75 \mathrm{~min}$. Phages were collected by centrifugation $\left(17 \mathrm{~min}, 12500 \mathrm{~g}, 4^{\circ} \mathrm{C}\right)$. Phage pellets

478 were resuspended in $1.2 \mathrm{ml} \mathrm{PBS}$, suspensions were cleared $\left(5 \mathrm{~min}, 12500 \mathrm{~g}, 25^{\circ} \mathrm{C}\right)$ and supernatants

479 containing phages were stored.

480

481 Cell culture

482 NIH3T3 and HEK293T cells (ATCC) were maintained in DMEM containing 10\% FBS, 2 mM L-

483 glutamine and $100 \mathrm{U} / \mathrm{ml}$ penicillin/streptomycin (Thermo Scientific) and cultured at $37^{\circ} \mathrm{C}$ and $5 \%$

$484 \mathrm{CO}_{2}$. For sub-culturing, medium was aspirated, cells were washed with PBS and detached with

485 Trypsin-EDTA $0.25 \%$ (Thermo Scientific). Detachment reactions were stopped with culture

486 medium and cells were seeded at desired densities. Cell stocks were prepared by resuspending cell

487 aliquots in FBS with $10 \%$ DMSO and freezing them slowly at $-80^{\circ} \mathrm{C}$. Frozen aliquots were then

488 moved to liquid nitrogen for long-term storage. All cell lines were regularly tested for mycoplasma

489 contamination.

490

\section{$491 \quad$ Plasmid transfection of HEK293T cells}

492 One day before transfection, $2 \times 10^{6}$ HEK293T cells were seeded in $10 \mathrm{~cm}$ dishes (Corning) in

493 complete culture medium (as described in section 'Cell culture'). Transfection was performed 494 using GeneJuice reagent (Fisher Scientific). 600 $\mu 1$ Opti-MEM and $12 \mu 1$ GeneJuice were mixed in

$4951.5 \mathrm{ml}$ tubes, vortexed shortly and spun down. $4 \mu \mathrm{g}$ of plasmid DNA (either pCAG (Addgene ID:

496 11160), pCAC-EGFP (Addgene ID: 89684) or pCAC-EGFP (Addgene ID: 32601)) were added, 
497 tubes were vortexed shortly and spun down. Transfection mix was added dropwise to HEK293T

498 cells. Cells were grown for $24 \mathrm{~h}$ at $37^{\circ} \mathrm{C}$ and $5 \% \mathrm{CO}_{2}$ to allow transgene expression. Successful

499 transfection was assessed by fluorescence microscopy on an EVOS M5000.

501 Flow cytometry for detection of phage binding

502 Harvested cell lines or thawed PBMCs (see PHAGE-ATAC workflow for harvest and thawing 503 protocol) were resuspended in FC buffer (above) and incubated with respective phage nanobodies

504 for $20 \mathrm{~min}$ on a rotator at $4^{\circ} \mathrm{C}$. Cells were centrifuged and washed with cold $\mathrm{FC}$ buffer twice to 505 remove unbound phages (all centrifugation steps were $350 \mathrm{~g}, 4 \mathrm{~min}, 4^{\circ} \mathrm{C}$ ). For optimization of 506 fixation and lysis conditions, cells were fixed using indicated formaldehyde concentrations 507 (Thermo Scientific) and permeabilized with depicted lysis buffers. Cells were resuspended in FC 508 buffer and anti-M13 antibody (Sino Biological, 11973-MM05T-50) was added at 1:500 dilution.

509 After 10min on ice, cells were washed twice in FC buffer and anti-mouse Fc Alexa Fluor 647510 conjugated secondary antibody (Thermo Scientific, A-21236) was added at 1:500 dilution. Cells

511 were incubated for 10min on ice, washed twice in FC buffer and resuspended in Sytox Blue

512 (Thermo Scientific) containing FC buffer for live/dead discrimination according to manufacturer's 513 instructions. In indicated cases, cells were stained with anti-CD4-FITC (clone OKT4, BioLegend) 514 at 1:500 dilution, hereby no anti-M13 and anti-mouse Fc antibodies were used. Stained cells were 515 analyzed using a CytoFLEX LX Flow Cytometer (Beckman Coulter) at the Broad Institute Flow 516 Cytometry Facility. Flow cytometry data were analyzed using FlowJo software v.10.6.1. 
519 For cell line "species mixing" experiment, culture medium was aspirated, cell lines were washed

520 with PBS, harvested using Trypsin-EDTA 0.25\% (Thermo Scientific), resuspended in DMEM

521 containing 10\% FBS, centrifuged, washed with PBS and resuspended in FC buffer. For PBMC

522 and CD8 T cell experiments, cryopreserved PBMCs or CD8 T cells (AllCells) were thawed,

523 washed in PBS and resuspended in cold Flow cytometry buffer (FC buffer; PBS containing 2\%

524 FBS). All centrifugation steps were carried out at $350 \mathrm{~g}, 4 \mathrm{~min}, 4^{\circ} \mathrm{C}$ unless stated otherwise.

525

526 Cells were incubated with phages on a rotating wheel for $20 \mathrm{~min}$ at $4^{\circ} \mathrm{C}$. After three washes in FC

527 buffer, cells were fixed in PBS containing 1\% formaldehyde (Thermo Scientific) for 10min at

528 room temperature. Fixation was quenched by addition of $2.5 \mathrm{M}$ glycine to a final concentration of

$5290.125 \mathrm{M}$. Cells were washed twice in FC buffer and permeabilized using lysis buffer (10mM Tris-

$530 \mathrm{HCl} \mathrm{pH} 7.5,10 \mathrm{mM} \mathrm{NaCl}, 3 \mathrm{mM} \mathrm{MgCl}_{2}, 0.1 \% \mathrm{NP}-40,1 \% \mathrm{BSA}$ ) for $3 \mathrm{~min}$ on ice. This buffer was

531 used, as we found that standard 10x Genomics scATAC lysis buffer results in loss of pNb cell

532 staining (Supp. Fig. 9). After lysis, cells were washed by addition of $1 \mathrm{ml}$ cold wash buffer (lysis

533 buffer without NP-40), inverted and centrifuged (5min, 500g, $\left.4^{\circ} \mathrm{C}\right)$. Supernatant was aspirated and

534 the cell pellet was resuspended in 1x Nuclei Dilution Buffer (10x Genomics). Cell aliquots were

535 mixed with Trypan Blue and counting was performed using a Countess II FL Automated Cell

536 Counter. Processing of cells for tagmentation, loading of 10x Genomics chips and droplet

537 encapsulation via the 10x Genomics Chromium controller microfluidics instrument was performed

538 according to Chromium Single Cell ATAC Solution protocol.

540 For species-mixing, a single 10x channel was 'super-loaded' with 20,000 cells. Linear

541 amplification and droplet-based indexing were performed as described in the 10x ATAC protocol 
542 on a C1000 Touch Thermal cycler with 96-Deep Well Reaction Module (BioRad). After linear

543 PCR, droplet emulsions were broken, barcoded products were purified using MyONE silane bead

544 cleanup and eluted in $40 \mu 1$ elution buffer I (Chromium Single Cell ATAC Solution protocol). At

545 this point eluates were split for PDT and ATAC library preparation. Whereas $5 \mu 1$ eluate were used

546 for PDT library preparation as described below, the remaining $35 \mu 1$ eluate were used for scATAC

547 library generation (according to Chromium Single Cell ATAC Solution protocol). Splitting

548 samples at this point is not expected to result in a loss of library complexity as PDTs and ATAC

549 fragments already underwent amplification via linear PCR.

550

551 The aliquot for PDT library preparation was used for PDT-specific PCR in a $100 \mu 1$ reaction using

552 2x KAPA polymerase and primers EF147 and EF91, cycling conditions were: $95^{\circ} \mathrm{C} 3 \mathrm{~min}$, 20cycles

$55395^{\circ} \mathrm{C} 20 \mathrm{sec}, 60^{\circ} \mathrm{C} 30 \mathrm{sec}, 72^{\circ} 20 \mathrm{sec}$; final extension $72^{\circ} \mathrm{C} 5 \mathrm{~min}$. Amplified PDT products were

554 purified by addition of $65 \mu 1$ SPRIselect beads (Beckman Coulter), $160 \mu 1$ supernatants were saved

555 and incubated with $192 \mu 1$ SPRIselect. Beads were washed twice with $800 \mu 180 \%$ ethanol and the

556 PDT library was eluted in $40 \mu 1$ buffer EB (Qiagen).

558 Concentration of PDT libraries was determined and 15ng were used for $100 \mu$ l indexing PCR 559 reactions using 50 $\mu 1$ Amp-Mix (10x Genomics), 7.5 $\mu 1$ SI-PCR Primer B (10x Genomics) and 2.5 $\mu 1$

560 i7 sample index-containing primers (10x Genomics), cycling conditions were: $98^{\circ} \mathrm{C} 45 \mathrm{sec}$; 6 cycles

$56198^{\circ} \mathrm{C} 20 \mathrm{sec}, 67^{\circ} \mathrm{C} 30 \mathrm{sec}, 72^{\circ} 20 \mathrm{sec}$; final extension $72^{\circ} \mathrm{C} 1 \mathrm{~min}$. Indexed PDT libraries were 562 purified by addition of $120 \mu \mathrm{l}$ SPRIselect and eluted in $40 \mu 1$ buffer EB. The concentration of final

563 libraries was determined using a Qubit dsDNA HS Assay kit (Invitrogen) and size distribution was

564 examined by running a High Sensitivity DNA chip on a Bioanalyzer 2100 system (Agilent). 
566 PDT and ATAC libraries were pooled and paired-end sequenced $(2 \times 34$ cycles) using Nextseq

567 High Output Cartridge kits on a Nextseq 550 machine (Illumina). Raw sequencing data were

568 demultiplexed with CellRanger-ATAC mkfastq. ATAC fastqs were used for alignment to the

569 GRCh38 or mm10 reference genomes using CellRanger-ATAC count version 1.0.

\section{Computational workflow for generation of PDT count matrices}

572 PDT fastqs were obtained by running CellRanger-ATAC mkfastq on raw sequencing data and

573 custom UNIX code was used to derive PDT-cell barcode count tables. For each lane, using 'grep

574 -B1' function, PDT_R3 fastqs were searched for each CDR3 barcode sequence (Supplementary

575 Table 4) and corresponding sequencing cluster information was derived. Cluster information was

576 used to derive corresponding cell barcodes from PDT_R2 fastqs by using 'fgrep -A1 -f'. Files

577 containing identified cell barcodes from all four lanes were concatenated, the reverse complement

578 of cell barcode sequences was generated using 'tr ACGTacgt TGCAtgca' and barcodes were

579 filtered via 'fgrep -f' using the cell barcodes called by CellRanger-ATAC count. Unique cell

580 barcode occurrences were counted.

\section{Analysis of species mixing PHAGE-ATAC experiment}

583 PHAGE-ATAC sequencing data from the species-mixing experiment was demultiplexed using

584 CellRanger-ATAC mkfastq and generated ATAC fastqs were processed with CellRanger-ATAC

585 count to filter reads, trim adapters, align reads to both GRCh38 and mm10 reference genomes,

586 count barcodes, identify transposase cut sites, detect accessible chromatin peaks and to identify

587 cutoffs for cell barcode calling. The "force-cells" parameter was not set. Barcodes were classified 
588 as human or mouse if $>90 \%$ of barcode-associated fragments aligned to GRCh38 or mm10,

589 respectively. Cutoffs for cell barcode calling were $>3,000$ ATAC fragments overlapping peaks for

590 human and $>10,000$ for mouse barcodes (based on empirical density). Doublet barcodes were

591 defined as containing more than 10\% ATAC fragments aligning to both GRCh38 and mm10

592 reference genomes. The EGFP PDT count table was generated as described above by searching

593 PDT fastqs for the corresponding phage barcode (Supplementary Table 4) and deriving PDT-

594 associated cell barcodes via filtering using the entire list of called cell barcodes (human and

595 mouse).

596

597 After flow cytometry measurement of HEK293T-EGFP-GPI (EGFP $\left.{ }^{+}\right)$and HEK293T cells (EGFP-

598 ), FCS files were exported using CytExpert Software (Beckman Coulter). Values for forward 599 scatter (FSC area) and EGFP fluorescence (FITC area) were derived from FCS files. Human $600 \mathrm{EGFP}^{+}$and EGFP- cells were defined based on the distribution of EGFP PDT counts (for PHAGE601 ATAC) or EGFP fluorescence represented by FITC-area values (for flow cytometry) by setting a 602 gate at the minimum value in-between both populations.

603

604 Analysis of PBMC PHAGE-ATAC experiment

605 Sequencing data from two libraries of PBMCs were processed using CellRanger-ATAC count to 606 the GRChg38 reference genome using all default parameters, yielding 7,792 high-quality PBMCs 607 (no filtering was applied beyond the CellRanger-ATAC knee call). We downloaded processed 608 CITE-seq PBMC data (Stoeckius et al., 2017) from the Gene Expression Omnibus (GSE100866). 609 After removing spiked-in mouse cells, this published dataset was jointly analyzed with the 7,972 610 PBMCs profiled by PHAGE-ATAC. We performed data integration using canonical correlation 
611 analysis (Butler et al., 2018), using the 2,000 most variable RNA genes as is the default in Seurat.

612 Next, we performed RNA imputation for the ATAC-seq data using Seurat v3 with the default

613 settings (Stuart et al., 2019). Reduced dimensions and cell clusters were inferred using this merged

614 object via the first 20 canonical correlation components with the default Louvain clustering in

615 Seurat v3. Centered log ratio (CLR) normalized PDTs were visualized in the reduced dimension

616 space and a per-tag, per-cluster mean was further computed to further access staining efficiency

617 between the modalities (Figure 1N).

618

619 Cell annotations were derived based on well-established marker genes for PBMCs (Supp. Fig.

$620 \mathrm{10A}$ ), and the granulocyte population was corroborated by high overall fragments but low

621 proportion of fragments overlapping chromatin accessibility peaks. For protein-based clustering

622 and analyses, we identified T-cell clusters from the integrated embedding (using the

623 chromatin/RNA data) and then further stratified into subpopulations based on the abundance of

624 the CD4 and CD8 CLR PDT abundances (Supp. Fig. 10B). Differential gene activity scores

625 between these populations were then computed using the default functionality in Seurat/Signac

626 (Wilcoxon rank-sum test).

\section{Analysis of cell hashing PHAGE-ATAC experiment}

629 One channel of sequencing data from the hashed, combined CD8-enriched T cells was processed

630 using CellRanger-ATAC count via the GRCh38 reference genome using all default parameters, 631 yielding 8,366 high-quality PBMCs (no filtering was applied beyond the CellRanger-ATAC knee

632 call). As we suspected the presence of contaminating B-cells, we first characterized cell states 633 using latent semantic indexing (LSI)-based clustering and dimensionality reduction using Signac 
634 and Seurat (Stuart et al., 2019). Specifically, all detected peaks were used as input into LSI. The

635 first 20 LSI components (except for the first component, which was found to be correlated with

636 the per-cell sequencing depth) were used to define cell clusters using the default Louvain clustering

637 algorithm in Seurat. Per-cluster chromatin accessibility tracks were computed using a per million

638 fragments abundance for each cluster, as previously implemented (Lareau et al., 2020). These

639 chromatin accessibility tracks were used to annotate cell clusters based on promoter accessibility

640 of known marker genes.

641

642 To assign hash identities to cell barcodes, we utilized the HTODemux function from Seurat

643 (Stoeckius et al., 2018) with the positive.quantile parameter set at 0.98 . This yielded 703 doublets,

6441,225 negatives, and 6,438 singlets based on the abundance and distribution of CD8 hashtag PDTs.

645

646 To verify PHAGE-ATAC hashtag-based assignments, we performed mitochondrial DNA

647 genotyping using mgatk (Lareau et al., 2020) and nuclear genotyping and donor assignment using

648 souporcell (Heaton et al., 2020) with “--min_alt 8 --min_ref 8 --no_umi True -k 4 --skip_remap

649 True --ignore True" options, which resulted in $92.9 \%$ accuracy $(99.3 \%$ singlet accuracy, $74 \%$

650 overlap in called doublets), confirming the concordance of our hashing design.

652 Cloning of PANL, a synthetic high-complexity phage nanobody library

653 To generate randomized library inserts, three separate primer mixes (for long CDR3, medium

654 CDR3 and short CDR3 inserts) were used for PCR-mediated assembly. For short CDR3-inserts,

655 the primer mix contained $0.5 \mu 1$ each of polyacrylamide gel electrophoresis-purified EF42, EF43,

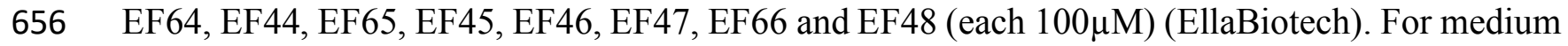


657 CDR3-inserts, EF67 was used instead of EF66. For long CDR3-inserts, EF68 was used instead of

658 EF66. Primer mixes were diluted 1:25 and 1 $\mu$ l of each mix was used for overlap-extension PCR

659 using Phusion (NEB). Four 50 $\mu 1$ reactions for each mix were performed using cycling conditions

$66098^{\circ} \mathrm{C} 1 \mathrm{~min} ; 20$ cycles $98^{\circ} \mathrm{C} 15 \mathrm{sec}, 60^{\circ} \mathrm{C} 30 \mathrm{sec}, 72^{\circ} 30 \mathrm{sec}$; final extension $72^{\circ} \mathrm{C} 5 \mathrm{~min}$. PCR

661 reactions of the same mix were pooled and purified by addition of $280 \mu 1$ AMPure XP beads

662 (Beckman Coulter). Beads were washed twice with $800 \mu 180 \%$ ethanol and assembled inserts were

663 eluted in $100 \mu 1$ water. Concentrations of each insert (long, medium, short) were determined and

664 pooled in a 1:2:1 molar ratio. Five identical 50 1 PCR reactions with pooled inserts and primers

665 EF40 and EF41 were performed using Phusion (NEB), cycling conditions were $98^{\circ} \mathrm{C} 1 \mathrm{~min}$;

66630 cycles $98^{\circ} \mathrm{C} 15 \mathrm{sec}, 62^{\circ} \mathrm{C} 30 \mathrm{sec}, 72^{\circ} 30 \mathrm{sec}$; final extension $72^{\circ} \mathrm{C} 5 \mathrm{~min}$. Amplified library insert

667 was pooled and purified by adding 350 $\mu 1$ AMPure XP beads (Beckman Coulter). Beads were

668 washed twice with $1 \mathrm{ml} 80 \%$ ethanol and library insert was eluted in $60 \mu 1$ water. Five identical

$66960 \mu 1$ restriction digest reactions for digest of $7.5 \mu \mathrm{g}$ library vector pDXinit-PAC with $2.5 \mu 1$ SapI

670 were performed. Library insert $(4.8 \mu \mathrm{g})$ was digested in a $30 \mu 1$ reaction using $2.5 \mu 1$ SapI. Digests

671 were incubated for $4 \mathrm{~h}$ at $37^{\circ} \mathrm{C}$ and loaded on $1 \%$ agarose gels. Bands corresponding to digested

672 library vector and insert were cut and products were extracted using GeneJet Gel Extraction Kit

673 (Thermo Scientific) and eluted in $40 \mu 1$ water. Five identical $100 \mu 1$ ligation reactions were

674 performed, each containing $1.25 \mu \mathrm{g}$ digested pDXinit-PAC, 450ng digested insert and $0.5 \mu 1 \mathrm{~T} 4$

675 ligase (NEB). Ligations were incubated for $16 \mathrm{~h}$ at $16^{\circ} \mathrm{C}$, heat-inactivated for $20 \mathrm{~min}$ at $65^{\circ} \mathrm{C}$ and

676 cooled to room temperature. $100 \mu 1$ AMPure XP beads were added to each ligation reaction, beads

677 were washed twice using $300 \mu 180 \%$ ethanol and ligation products were eluted in $15 \mu 1$ water and

678 pooled. Five electroporations in $2 \mathrm{~mm}$ cuvettes (BioRad) were performed, each using $90 \mu 1$ electro-

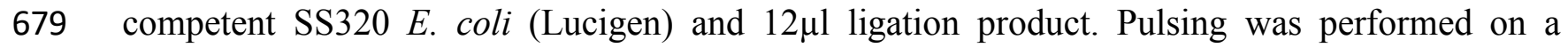


680 GenePulserXcell instrument (BioRad) with parameters 2.5kV, 200Ohm, 25 $\mu$ F. After

681 electroporation, bacterial suspensions were added to $120 \mathrm{ml}$ pre-warmed SOC and incubated for

$68230 \mathrm{~min}, 37^{\circ} \mathrm{C}, 225 \mathrm{rpm}$. An aliquot of library-carrying bacteria was saved at this point and used to

683 prepare a dilution series. Each dilution was plated on LB-Ampicillin plates. After overnight

684 incubation at $37^{\circ} \mathrm{C}$, colonies were counted, transformation efficiency was determined and library

685 complexity was estimated. The remaining $120 \mathrm{ml}$ of library-containing culture were added to

$6861.125 \mathrm{~L} 2 \mathrm{YT} / 2 \% / \mathrm{A} / \mathrm{T}$ and incubated overnight at $37^{\circ} \mathrm{C}, 240 \mathrm{rpm}$. The library-containing culture was

687 harvested, glycerol stocks were prepared and library aliquots were stored.

688

689 Analysis of picked PANL clones using PCR and Sanger sequencing

690 Library-containing bacteria were plated on LB-Ampicillin, incubated overnight, and colonies were 691 picked and inoculated in $8 \mathrm{ml} \mathrm{LB}-$ Ampicillin. Cultures were incubated for at least $8 \mathrm{~h}$ at $37^{\circ} \mathrm{C}$,

692 240rpm. Bacteria were harvested and plasmids isolated using GeneJet Plasmid Miniprep kit 693 (Thermo Scientific). PCR was performed to evaluate clone inserts. $10 \mu 1$ PCR reactions were set 694 up that contained 10ng of isolated plasmid, $0.5 \mu 1$ each of primers EF52 and EF53, and $4.5 \mu 12 \mathrm{x}$ 695 OneTaq Quick Load Master Mix (NEB). Cycling conditions were $94^{\circ} \mathrm{C} 4 \mathrm{~min}$; $28 \mathrm{cycles} 94^{\circ} \mathrm{C}$ $69615 \mathrm{sec}, 62^{\circ} \mathrm{C} 15 \mathrm{sec}, 68^{\circ} \mathrm{C} 30 \mathrm{sec}$; final extension $68 \mathrm{C} 5 \mathrm{~min}$. PCR reactions were analyzed on $2 \%$

697 agarose gels. Selected clones were analyzed by Sanger Sequencing using primer EF17. Observed 698 amino acid frequencies at hypervariable positions were assessed by analyzing Sanger sequences 699 of 25 picked clones.

700

701 Phage nanobody library production 
A PANL aliquot corresponding to $3 \times 10^{10}$ bacterial cells (around $5 \times$ coverage of the library) was transferred to $200 \mathrm{ml} 2 \mathrm{YT} / 2 \% / \mathrm{A} / \mathrm{T}$ and cultures were grown until OD600 $=0.5$ was reached $(\sim 2 \mathrm{~h})$.

704 Cultures were infected with $8 \mathrm{ml} \mathrm{M13K07}$ helper (NEB) for $60 \mathrm{~min}$ at $37^{\circ} \mathrm{C}$. Cultures were

705 harvested, supernatants discarded and bacterial pellets were resuspended in 1L 2YT/A/K. Cultures

706 were incubated overnight at $37^{\circ} \mathrm{C}, 250 \mathrm{rpm}$ for production of the input library of phage nanobody

707 particles. Bacterial cultures were harvested, supernatants collected and phages were precipitated 708 using PEG/NaCl as described earlier. Final phage pellets were resuspended in a total of 20ml PBS 709 and stored. Phage titers were determined by infecting a log-phase culture of SS320 with a dilution 710 series of the produced phage library and plating bacteria on LB-Ampicillin. Colonies were counted 711 and titers were calculated. Produced phage libraries were characterized by titers $>4 \times 10^{11} \mathrm{pfu} / \mathrm{ml}$.

\section{Phage display selection}

714 HEK293T cells were transfected either with pCAG or pCAG-EGFP-GPI as described above. Cells

715 were harvested, $10^{7}$ pCAG-transfected cells were resuspended in $1 \mathrm{ml}$ PBS containing $2 \%$ BSA

716 (PBS-BSA), and 8ml PANL library (1.6x10 $12 \mathrm{pfu})$ in PBS-BSA were added for counter-selection.

717 Samples were incubated for $1 \mathrm{~h}$ on a rotating wheel at $4^{\circ} \mathrm{C}$ and then centrifuged at $350 \mathrm{~g}, 5 \mathrm{~min}, 4^{\circ} \mathrm{C}$.

718 Supernatants containing phages were added to $10^{7}$ pCAG-EGFP-GPI expressing cells for positive

719 selection. After $1 \mathrm{~h}$ on a rotating wheel at $4^{\circ} \mathrm{C}$, samples were centrifuged $\left(350 \mathrm{~g}, 5 \mathrm{~min}, 4^{\circ} \mathrm{C}\right)$ and

720 washed 6 times with PBS-BSA to remove unbound phages. Cells were washed once in PBS,

721 centrifuged and cell pellets were resuspended in 500 $\mu 1$ Trypsin solution $(1 \mathrm{mg} / \mathrm{ml}$ Trypsin (Sigma

722 Aldrich) in PBS) to elute bound phages. Cells were incubated for 30min on a rotating wheel at

723 room temperature and digests were stopped by addition of AEBSF protease inhibitor (Sigma

724 Aldrich) to a final concentration of $0.5 \mathrm{mg} / \mathrm{ml}$. Samples were centrifuged $(400 \mathrm{~g}, 4 \mathrm{~min}$ at room 
725 temperature) and the supernatant containing eluted phages was used to infect $10 \mathrm{ml}$ of log-phase

$726 \mathrm{SS} 320(\mathrm{OD} 600=0.4)$. After infection for $40 \mathrm{~min}$ at $37^{\circ} \mathrm{C}$, cultures were added to $90 \mathrm{ml} 2 \mathrm{YT} / 2 \% / \mathrm{A} / \mathrm{T}$

727 and incubated overnight at $37^{\circ} \mathrm{C}, 250 \mathrm{rpm}$. Cultures containing output libraries were aliquoted and

728 glycerol stocks were prepared. Output library phage particles were prepared as described earlier

729 for PANL and used in subsequent selection rounds using the same protocol described here.

731 Acknowledgements

732 We thank L. Gaffney for assistance with figure illustrations and preparation, C. de Boer and other

733 members of the Regev laboratory for helpful discussion. We acknowledge support from the Broad

734 Institute Flow Cytometry Core facility. This research was supported by NHGRI grants 5RM1

735 HG006193 (Center for Cell Circuits), a gift from the Food Allergy Science Initiative, a gift from

736 the Manton Foundation, and HHMI (to AR). E.F. is supported by an EMBO Long-Term

737 fellowship. C.A.L. is supported by a Stanford Science Fellowship. A.R. was a Howard Hughes

738 Medical Institute Investigator (until July 31, 2020).

\section{Author Contributions}

741 E.F. conceived and designed the project with guidance from A.R. E.F. designed and performed

742 experiments. E.F. developed the PHAGE-ATAC computational workflow with input from C.A.L.

743 E.F. developed the PHAGE-ATAC experimental protocol with input from L.S.L. E.F. and C.A.L

744 analyzed the data. G.E. contributed to data analysis. A.R. provided project oversight and acquired

745 funding. E.F. and A.R. wrote the manuscript with input from all authors.

\section{Corresponding authors}


748 Correspondence to E.F. (efiskin@broadinstitute.org) and A.R. (aregev@broadinstitute.org)

\section{Competing Interests statement}

751 A.R. is a founder and equity holder of Celsius Therapeutics, an equity holder in Immunitas

752 Therapeutics and until August 31, 2020 was an SAB member of Syros Pharmaceuticals, Neogene

753 Therapeutics, Asimov and ThermoFisher Scientific. From August 1, 2020, A.R. is an employee of

754 Genentech. The Broad Institute has filed for a patent related to PHAGE-ATAC where E.F. and

755 A.R. are named inventors.

756

\section{References}

758 Butler, A., Hoffman, P., Smibert, P., Papalexi, E., and Satija, R. (2018). Integrating single-cell

759 transcriptomic data across different conditions, technologies, and species. Nat Biotechnol 36, 411-

760420.

761 Gebauer, M., and Skerra, A. (2009). Engineered protein scaffolds as next-generation antibody

762 therapeutics. Curr Opin Chem Biol 13, 245-255.

763 Geertsma, E.R., and Dutzler, R. (2011). A versatile and efficient high-throughput cloning tool for

764 structural biology. Biochemistry 50, 3272-3278.

765 Gehring, J., Hwee Park, J., Chen, S., Thomson, M., and Pachter, L. (2020). Highly multiplexed

766 single-cell RNA-seq by DNA oligonucleotide tagging of cellular proteins. Nat Biotechnol 38, 35-

76738.

768 Heaton, H., Talman, A.M., Knights, A., Imaz, M., Gaffney, D.J., Durbin, R., Hemberg, M., and

769 Lawniczak, M.K.N. (2020). Souporcell: robust clustering of single-cell RNA-seq data by genotype

770 without reference genotypes. Nat Methods 17, 615-620. 
771 Hoogenboom, H.R. (2005). Selecting and screening recombinant antibody libraries. Nat

772 Biotechnol 23, 1105-1116.

773 Ingram, J.R., Schmidt, F.I., and Ploegh, H.L. (2018). Exploiting Nanobodies' Singular Traits.

774 Annu Rev Immunol 36, 695-715.

775 Katzenelenbogen, Y., Sheban, F., Yalin, A., Yofe, I., Svetlichnyy, D., Jaitin, D.A., Bornstein, C.,

776 Moshe, A., Keren-Shaul, H., Cohen, M., et al. (2020). Coupled scRNA-Seq and Intracellular

777 Protein Activity Reveal an Immunosuppressive Role of TREM2 in Cancer. Cell 182, 872-885

$778 \mathrm{e} 819$.

779 Klein, A.M., Mazutis, L., Akartuna, I., Tallapragada, N., Veres, A., Li, V., Peshkin, L., Weitz,

780 D.A., and Kirschner, M.W. (2015). Droplet barcoding for single-cell transcriptomics applied to

781 embryonic stem cells. Cell 161, 1187-1201.

782 Kubala, M.H., Kovtun, O., Alexandrov, K., and Collins, B.M. (2010). Structural and

783 thermodynamic analysis of the GFP:GFP-nanobody complex. Protein Sci 19, 2389-2401.

784 Lareau, C.A., Duarte, F.M., Chew, J.G., Kartha, V.K., Burkett, Z.D., Kohlway, A.S., Pokholok,

785 D., Aryee, M.J., Steemers, F.J., Lebofsky, R., et al. (2019). Droplet-based combinatorial indexing

786 for massive-scale single-cell chromatin accessibility. Nat Biotechnol 37, 916-924.

787 Lareau, C.A., Ludwig, L.S., Muus, C., Gohil, S.H., Zhao, T., Chiang, Z., Pelka, K., Verboon, J.M.,

788 Luo, W., Christian, E., et al. (2020). Massively parallel single-cell mitochondrial DNA genotyping

789 and chromatin profiling. Nat Biotechnol.

790 Ludwig, L.S., Lareau, C.A., Ulirsch, J.C., Christian, E., Muus, C., Li, L.H., Pelka, K., Ge, W.,

791 Oren, Y., Brack, A., et al. (2019). Lineage Tracing in Humans Enabled by Mitochondrial

792 Mutations and Single-Cell Genomics. Cell 176, 1325-1339 e1322. 
793 Ma, A., McDermaid, A., Xu, J., Chang, Y., and Ma, Q. (2020). Integrative Methods and Practical

794 Challenges for Single-Cell Multi-omics. Trends Biotechnol 38, 1007-1022.

795 Macosko, E.Z., Basu, A., Satija, R., Nemesh, J., Shekhar, K., Goldman, M., Tirosh, I., Bialas,

796 A.R., Kamitaki, N., Martersteck, E.M., et al. (2015). Highly Parallel Genome-wide Expression

797 Profiling of Individual Cells Using Nanoliter Droplets. Cell 161, 1202-1214.

798 McGinnis, C.S., Patterson, D.M., Winkler, J., Conrad, D.N., Hein, M.Y., Srivastava, V., Hu, J.L.,

799 Murrow, L.M., Weissman, J.S., Werb, Z., et al. (2019). MULTI-seq: sample multiplexing for

800 single-cell RNA sequencing using lipid-tagged indices. Nat Methods 16, 619-626.

801 McMahon, C., Baier, A.S., Pascolutti, R., Wegrecki, M., Zheng, S., Ong, J.X., Erlandson, S.C.,

802 Hilger, D., Rasmussen, S.G.F., Ring, A.M., et al. (2018). Yeast surface display platform for rapid

803 discovery of conformationally selective nanobodies. Nat Struct Mol Biol 25, 289-296.

804 Miersch, S., and Sidhu, S.S. (2012). Synthetic antibodies: concepts, potential and practical

805 considerations. Methods 57, 486-498.

806 Mimitou, E.P., Cheng, A., Montalbano, A., Hao, S., Stoeckius, M., Legut, M., Roush, T., Herrera,

807 A., Papalexi, E., Ouyang, Z., et al. (2019). Multiplexed detection of proteins, transcriptomes,

808 clonotypes and CRISPR perturbations in single cells. Nat Methods 16, 409-412.

809 Paul, F., Arkin, Y., Giladi, A., Jaitin, D.A., Kenigsberg, E., Keren-Shaul, H., Winter, D., Lara-

810 Astiaso, D., Gury, M., Weiner, A., et al. (2015). Transcriptional Heterogeneity and Lineage

811 Commitment in Myeloid Progenitors. Cell 163, 1663-1677.

812 Peterson, V.M., Zhang, K.X., Kumar, N., Wong, J., Li, L., Wilson, D.C., Moore, R., McClanahan, 813 T.K., Sadekova, S., and Klappenbach, J.A. (2017). Multiplexed quantification of proteins and

814 transcripts in single cells. Nat Biotechnol 35, 936-939. 
815 Pollock, S.B., Hu, A., Mou, Y., Martinko, A.J., Julien, O., Hornsby, M., Ploder, L., Adams, J.J.,

816 Geng, H., Muschen, M., et al. (2018). Highly multiplexed and quantitative cell-surface protein

817 profiling using genetically barcoded antibodies. Proc Natl Acad Sci U S A 115, 2836-2841.

818 Roobrouck, A., Stortelers, C., Vanlandschoot, P., Staelens, S., Conde, M., Soares, H., and Schols, 819 D. (2016). Bispecific Nanobodies. US 2016/0251440 A1.

820 Rothbauer, U., Zolghadr, K., Tillib, S., Nowak, D., Schermelleh, L., Gahl, A., Backmann, N.,

821 Conrath, K., Muyldermans, S., Cardoso, M.C., et al. (2006). Targeting and tracing antigens in live

822 cells with fluorescent nanobodies. Nat Methods 3, 887-889.

823 Satpathy, A.T., Granja, J.M., Yost, K.E., Qi, Y., Meschi, F., McDermott, G.P., Olsen, B.N.,

824 Mumbach, M.R., Pierce, S.E., Corces, M.R., et al. (2019). Massively parallel single-cell chromatin

825 landscapes of human immune cell development and intratumoral T cell exhaustion. Nat Biotechnol $826 \quad 37,925-936$.

827 Smith, G.P. (1985). Filamentous fusion phage: novel expression vectors that display cloned 828 antigens on the virion surface. Science $228,1315-1317$.

829 Stoeckius, M., Hafemeister, C., Stephenson, W., Houck-Loomis, B., Chattopadhyay, P.K.,

830 Swerdlow, H., Satija, R., and Smibert, P. (2017). Simultaneous epitope and transcriptome

831 measurement in single cells. Nat Methods 14, 865-868.

832 Stoeckius, M., Zheng, S., Houck-Loomis, B., Hao, S., Yeung, B.Z., Mauck, W.M., 3rd, Smibert, 833 P., and Satija, R. (2018). Cell Hashing with barcoded antibodies enables multiplexing and doublet 834 detection for single cell genomics. Genome Biol 19, 224.

835 Stuart, T., Butler, A., Hoffman, P., Hafemeister, C., Papalexi, E., Mauck, W.M., 3rd, Hao, Y., 836 Stoeckius, M., Smibert, P., and Satija, R. (2019). Comprehensive Integration of Single-Cell Data. 837 Cell 177, 1888-1902 e1821. 
bioRxiv preprint doi: https://doi.org/10.1101/2020.10.01.322420; this version posted October 2, 2020. The copyright holder for this preprint

(which was not certified by peer review) is the author/funder, who has granted bioRxiv a license to display the preprint in perpetuity. It is made available under aCC-BY-NC-ND 4.0 International license.

838 Tavernier, J., Cauwels, A., Kley, N., and Gerlo, S. (2017). CD8 Binding Agents. WO 2017/134306

839 Al.

840 
bioRxiv preprint doi: https://doi.org/10.1101/2020.10.01.322420; this version posted October 2, 2020. The copyright holder for this preprint (which was not certified by peer review) is the author/funder, who has granted bioRxiv a license to display the preprint in perpetuity. It is made available under aCC-BY-NC-ND 4.0 International license.

Figure 1

A

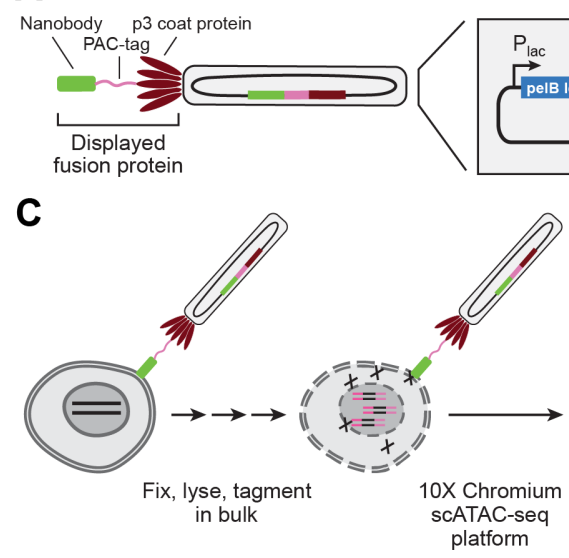

D

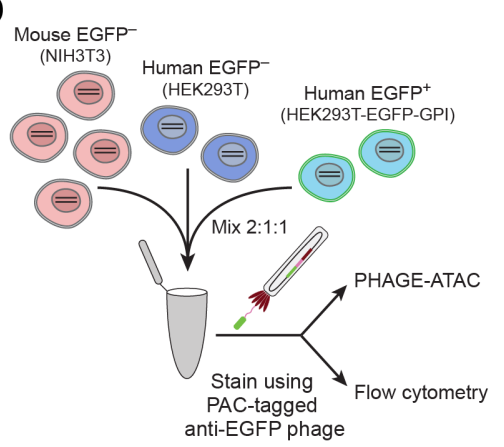

PHAGE-ATAC M13 phagemid

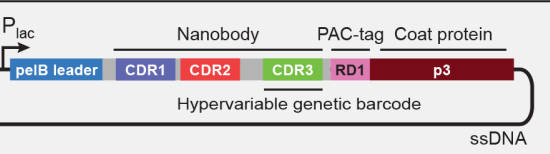

B

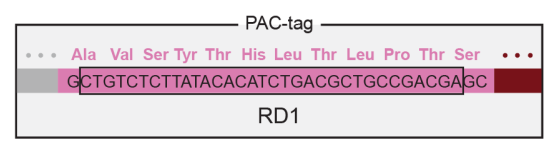

G
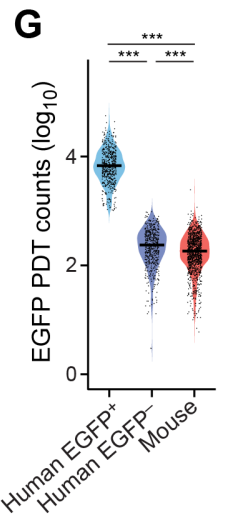

L

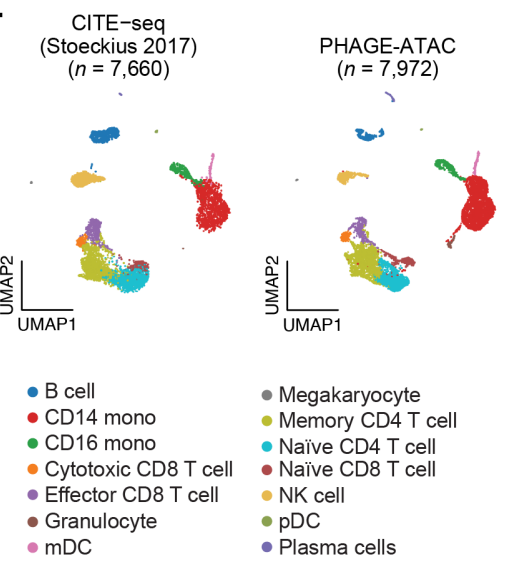

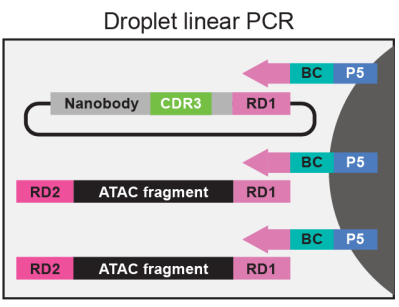

E

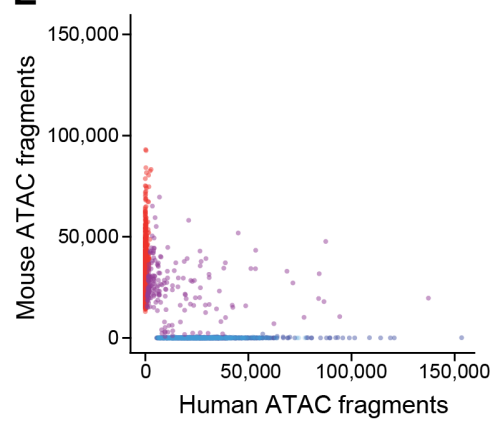

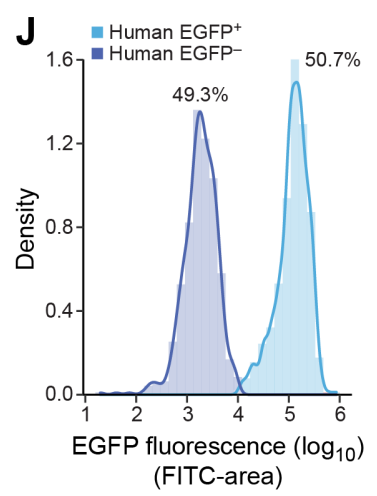

(FITC-area)
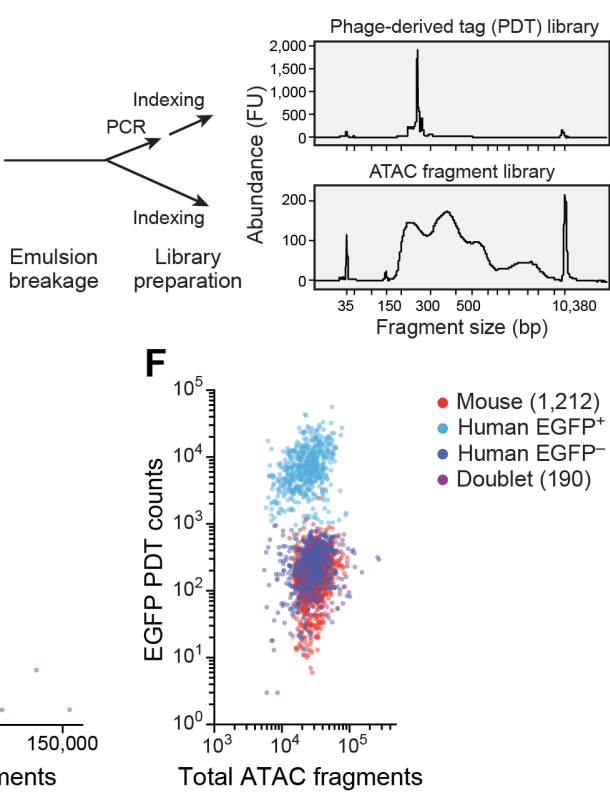
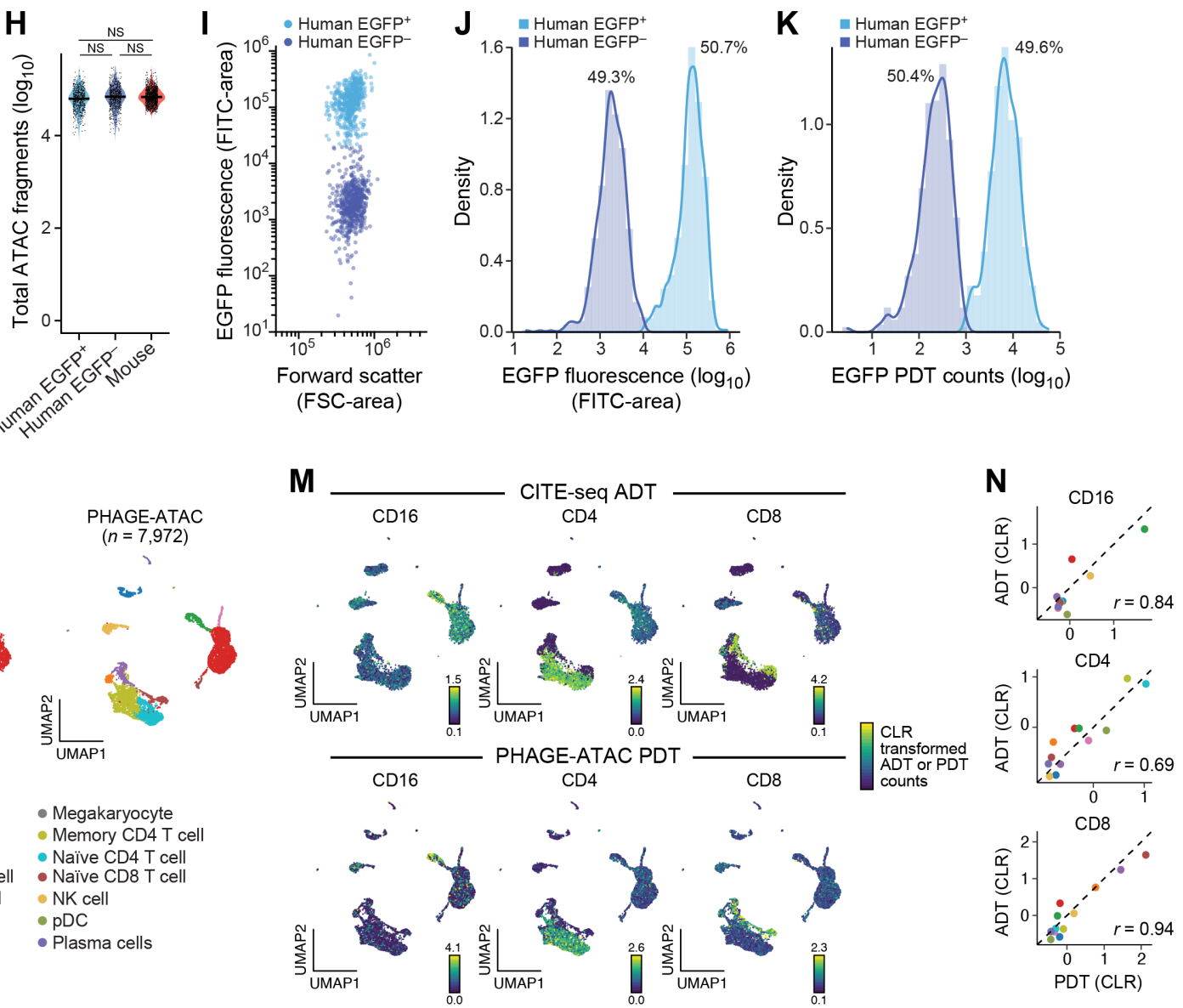
A

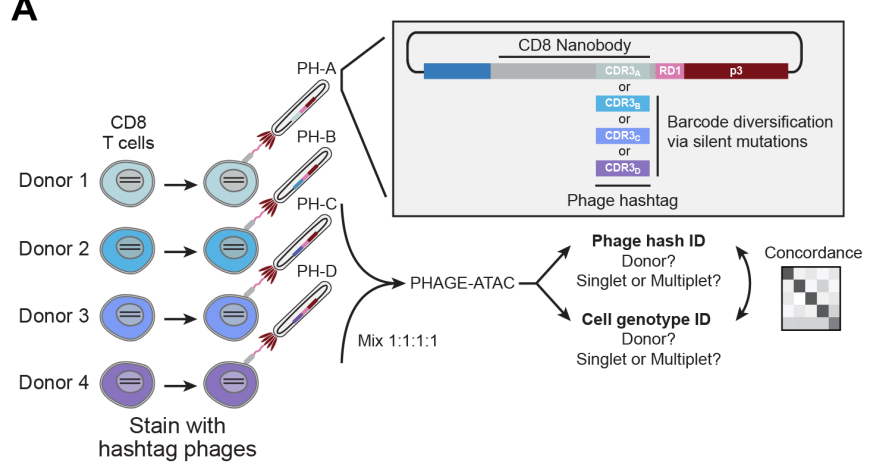

B

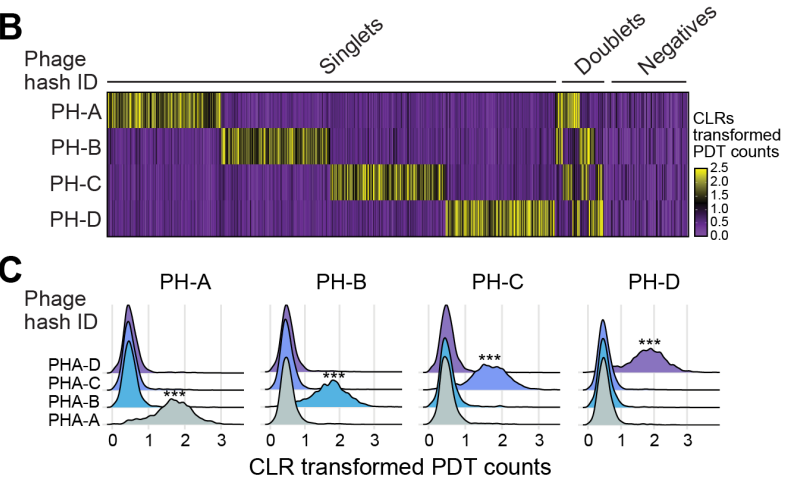

D
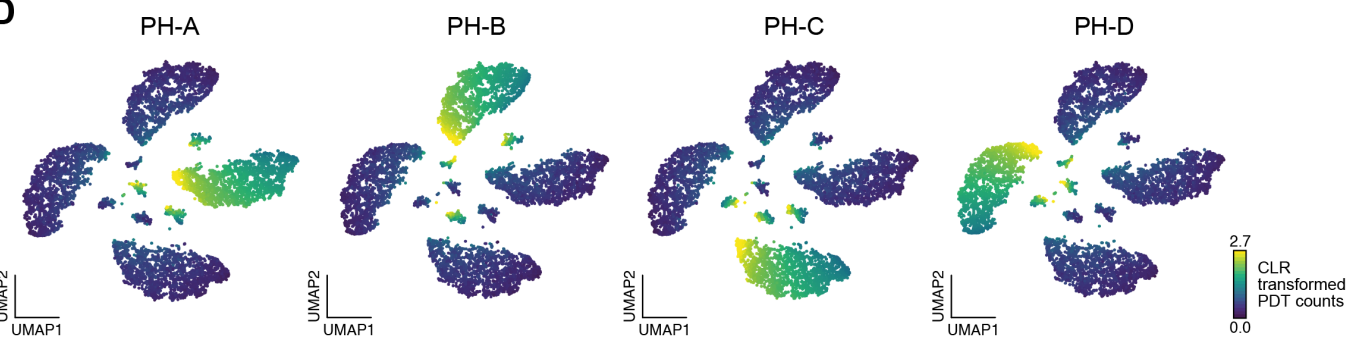

- Singlet • Doublet

E

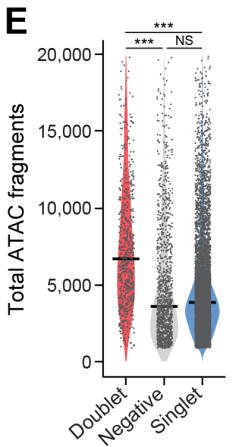

I

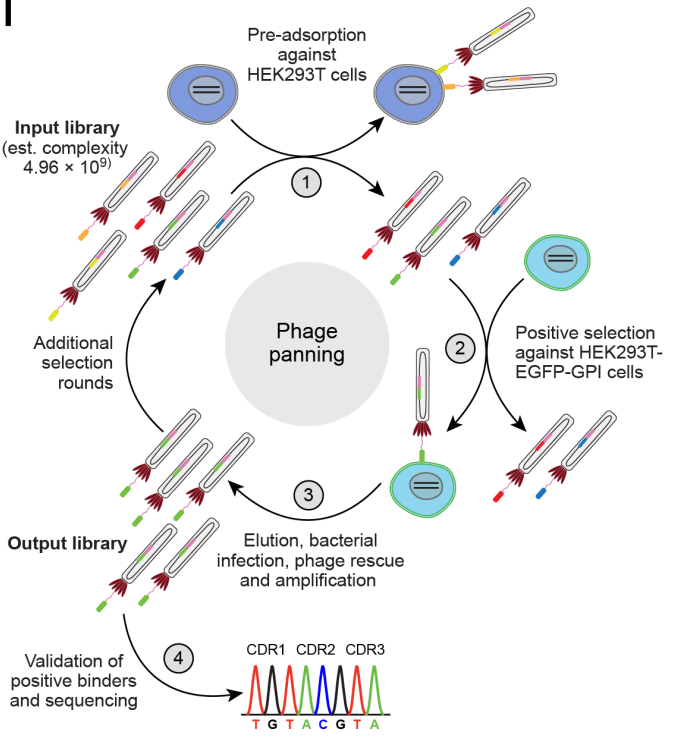

L

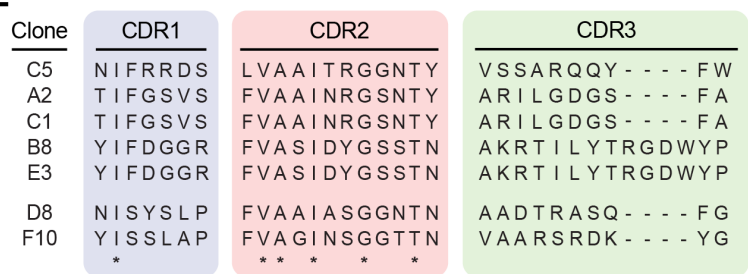

G
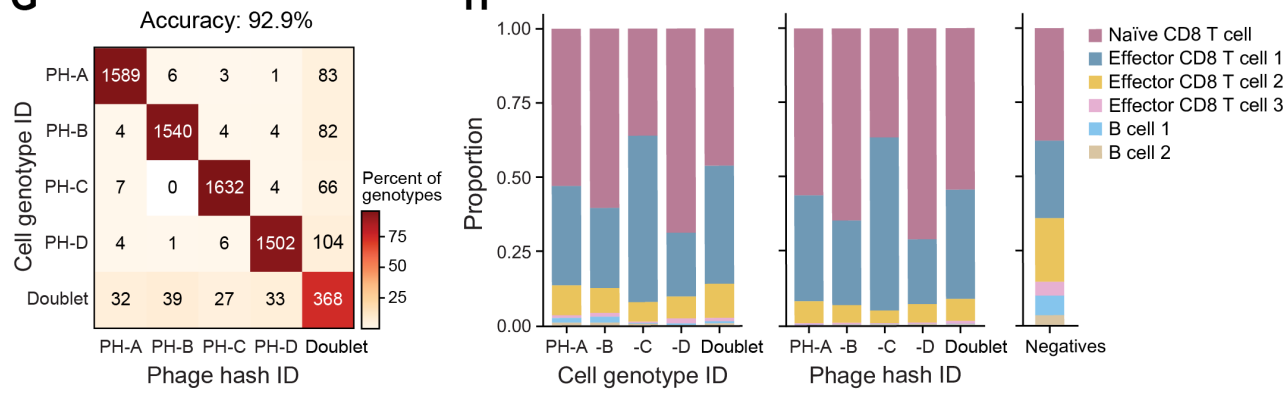

Figure 2

J

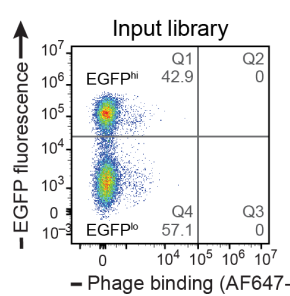

K

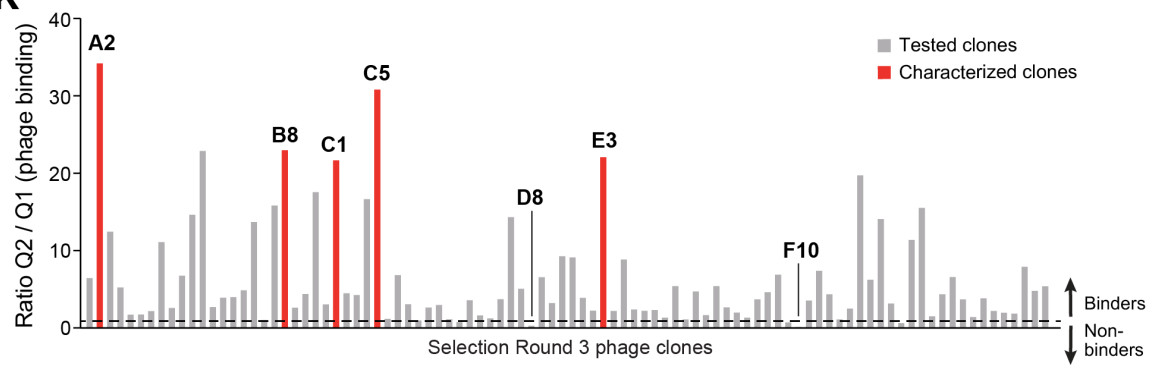

Selection output library

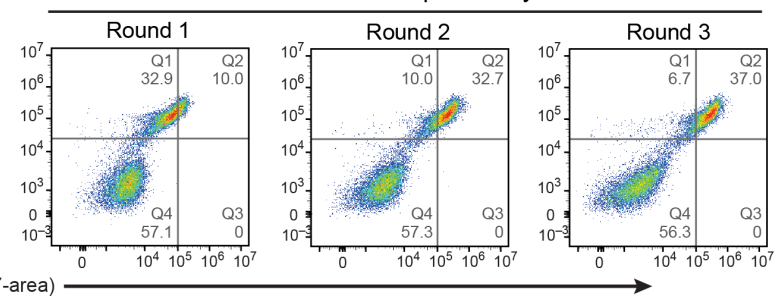

\begin{tabular}{c} 
CDR3 length \\
\hline Medium \\
Medium \\
Medium \\
Long \\
Long \\
Medium \\
Medium
\end{tabular}

M
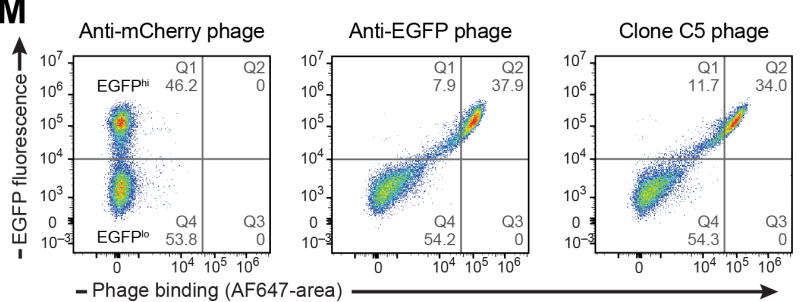
bioRxiv preprint doi: https://doi.org/10.1101/2020.10.01.322420; this version posted October 2, 2020. The copyright holder for this preprint (which was not certified by peer review) is the author/funder, who has granted bioRxiv a license to display the preprint in perpetuity. It is made available under aCC-BY-NC-ND 4.0 International license.

\section{Supp. Figure 1}

A Nanobody-displaying phages (PHAGE-ATAC)

Genetically encoded barcode
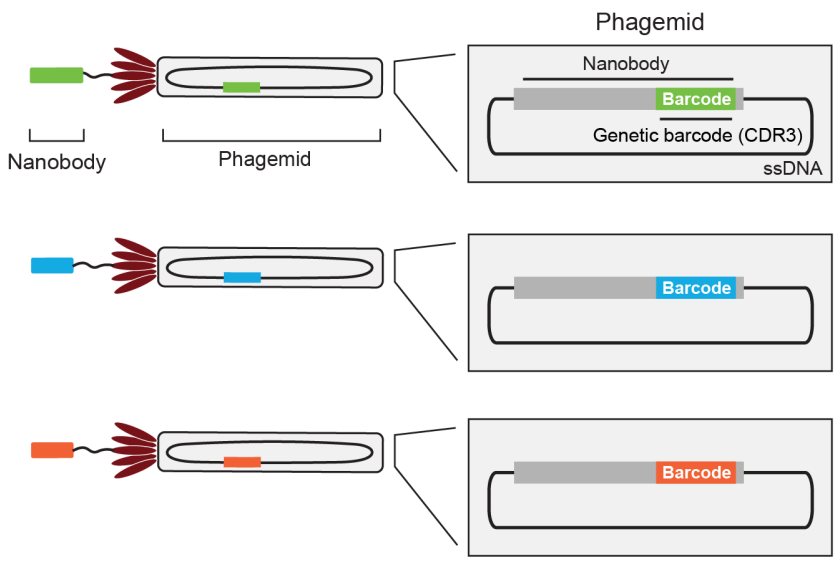

B Antibody-oligonucleotide conjugates (CITE-seq, REAP-seq) Chemically conjugated barcode
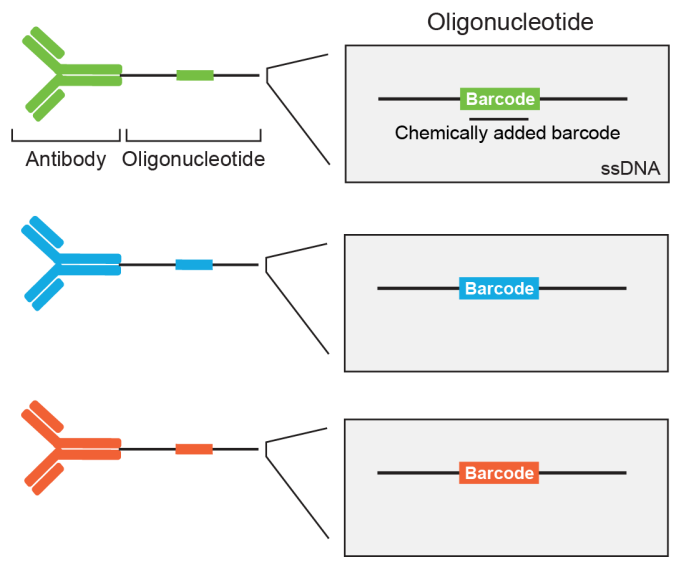
bioRxiv preprint doi: https://doi.org/10.1101/2020 10.01.322420; this version posted October 2, 2020. The copyright holder for this preprint (which was not certified by peer review) is the author/funder, who has granted bioRxiv a license to display the preprint in perpetuity. It is made available under aCC-BY-NC-ND 4.0 International license.

\section{Supp. Figure 2}

A

10X ATAC

bead oligo

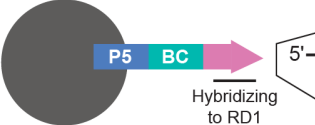

5'-AATGATACGgCGACCACCGAGATCTACACNNNNNNNNNNNNNNNNTCGTCGGCAGCGTC-3'

Hybridizing
to RD1

Hybridizing
to RD1

B

Phagemid (dsDNA)

RD1 in bottom strand

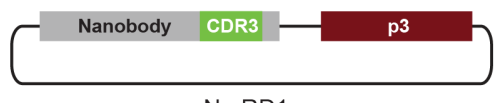

No RD1

$5^{\prime}$ - Nanobody CTG TCT CTT ATA CAC ATC TGA CGC TGC CGA CGA $3^{\prime}$ - Nanobody GAC AGA GAA TAT GTG TAG ACT GCG ACG GCT GC ... Leu Ser Leu lle His lle STOP

$\downarrow \begin{aligned} & \text { Change reading frame } \\ & \text { across the tag }\end{aligned}$

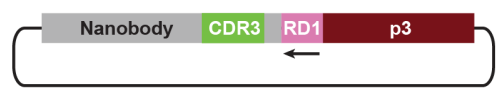

PAC tag (RD1 3'-5')
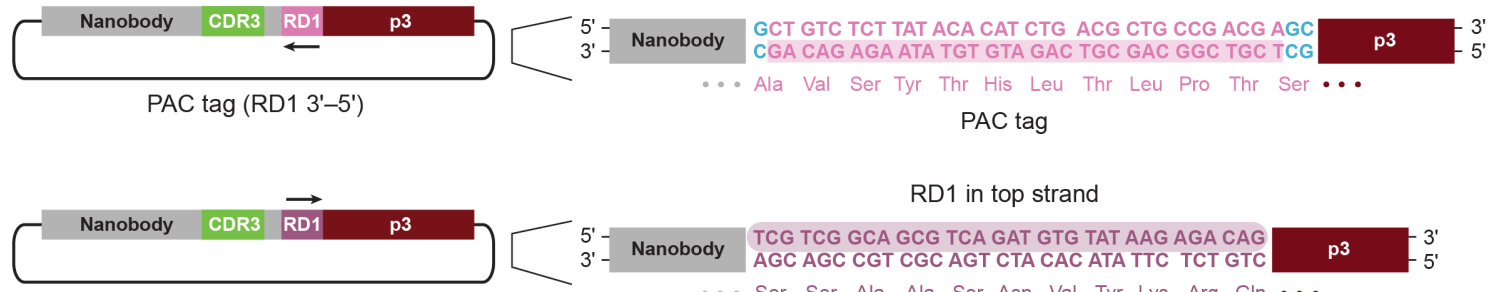

RD1 in top strand

RD1 5'-3'

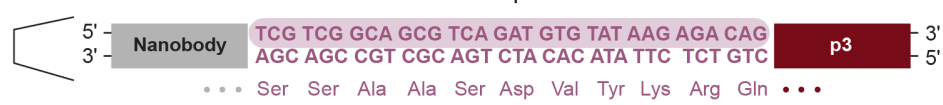

C

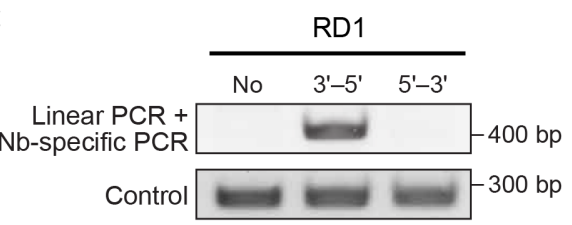

BC P5

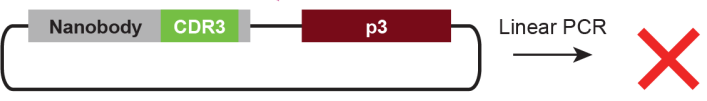

BC P5
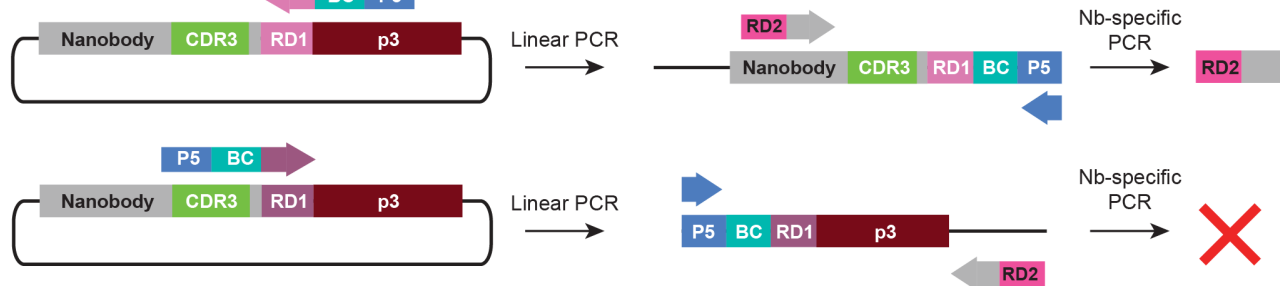

\begin{tabular}{l|l|l|l} 
Nanobody & CDR3 & RD1 & p3
\end{tabular}

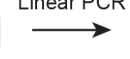


bioRxiv preprint doi: https://doi.org/10.1101/2020 10.01322420; this version posted October 2, 2020. The copyright holder for this preprint (which was not certified by peer review) is the author/funder, who has granted bioRxiv a license to display the preprint in perpetuity. It is made available under aCC-BY-NC-ND 4.0 International license.

\section{Supp. Figure 3}

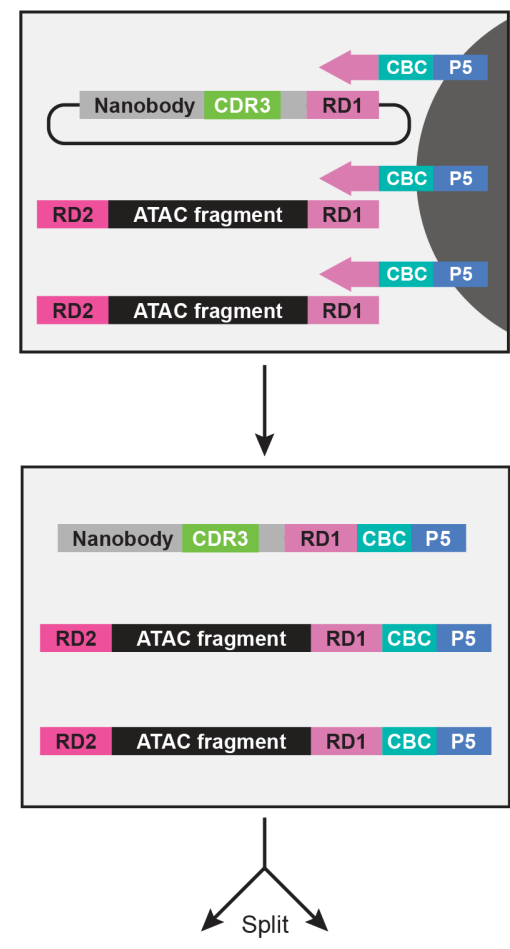

Droplet

linear PCR

Emulsion

breakage

RD2

Nanobody CDR3 RD1 CBC P5

Constant nanobody

region flanking CDR3

used as PCR handle

Phage-derived

tag PCR

\begin{tabular}{|l|l} 
P7 & i7 \\
\hline
\end{tabular}

RD2 CDR3

RD1 CBC P5

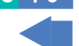

$\downarrow \begin{aligned} & \text { Index } \\ & \text { PCR }\end{aligned}$

$\begin{array}{lllllll}\text { P7 } & \text { i7 } & \text { RD2 } & \text { CDR3 } & \text { RD1 } & \text { CBC } & \text { P5 }\end{array}$

Phage-derived tag (PDT) library

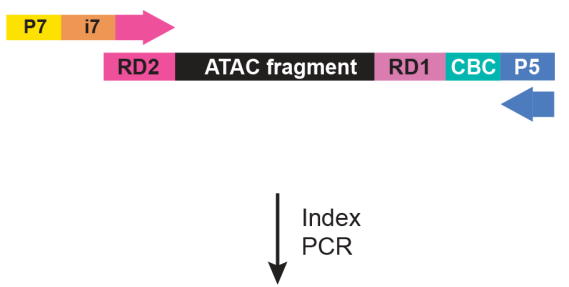

$\begin{array}{lllllll}\text { P7 } & \text { i7 } & \text { RD2 } & \text { ATAC fragment } & \text { RD1 } & \text { CBC } & \text { P5 }\end{array}$

ATAC fragment library 
bioRxiv preprint doi: https://doi.org/10.1101/2020.10.01.322420; this version posted October 2, 2020. The copyright holder for this preprint (which was not certified by peer review) is the author/funder, who has granted bioRxiv a license to display the preprint in perpetuity. It is made available under aCC-BY-NC-ND 4.0 International license.

\section{Supp. Figure 4}

A

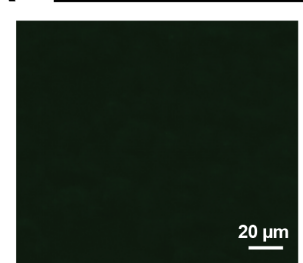

No EGFP (pCAG)
HEK293T

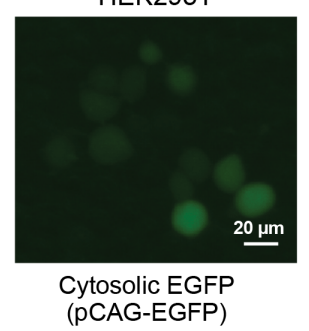

B

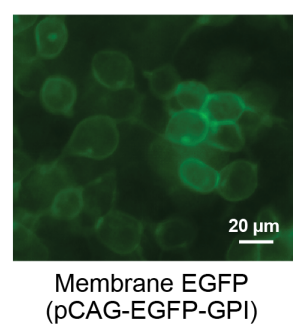

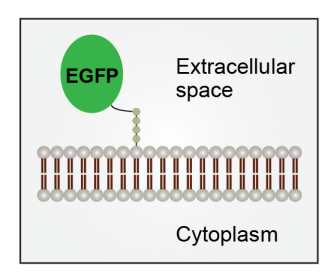

C

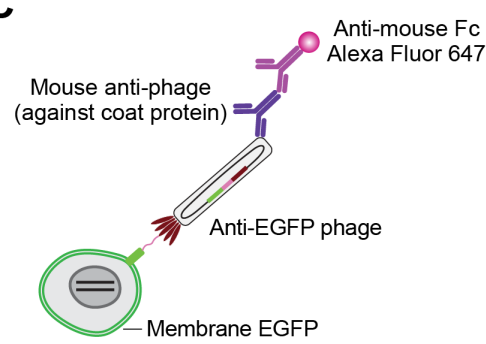

D
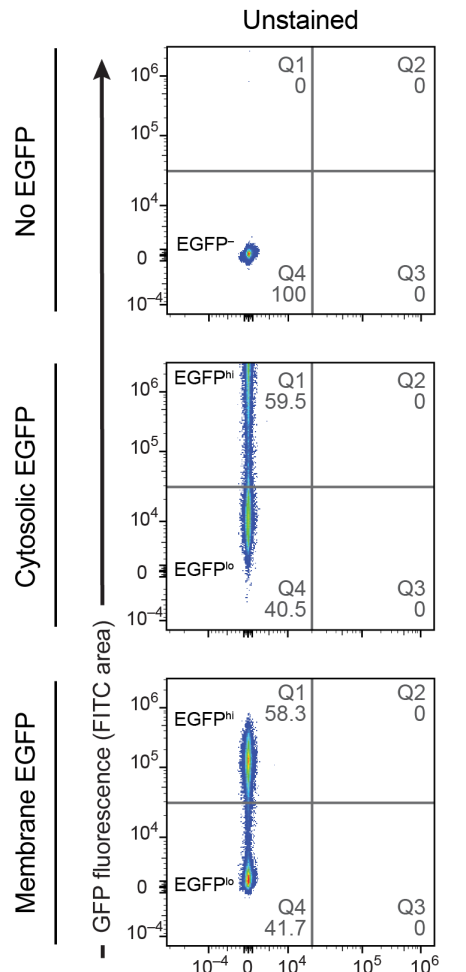

- Phage binding (AF647-area)

F

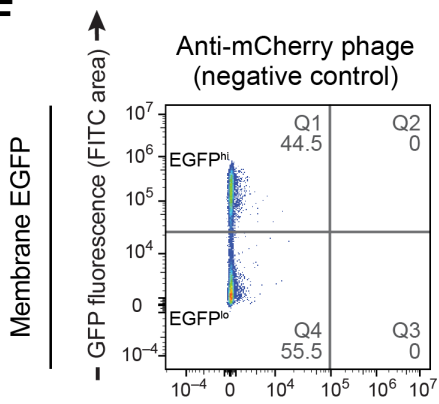

Anti-EGFP phage PAC-tag (RD1 3'-5')

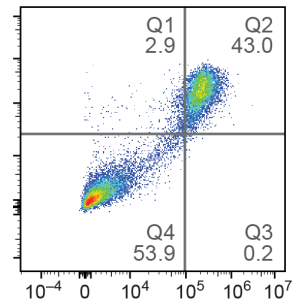

- Phage binding (AF647-area)
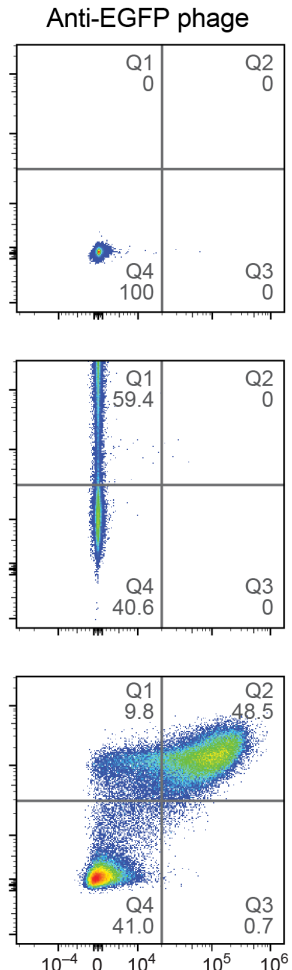

E Staining controls

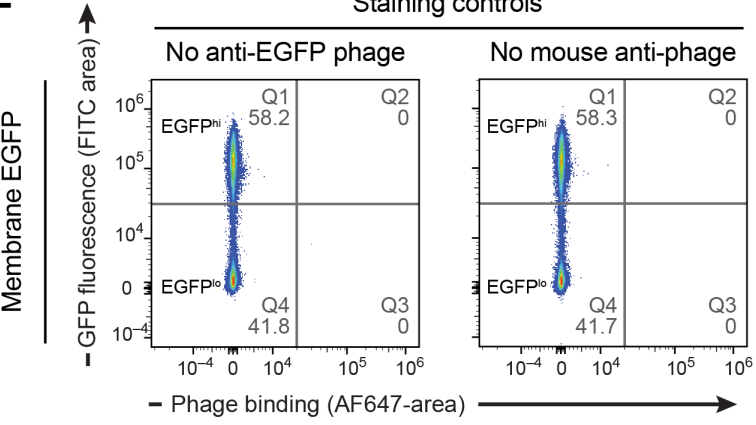

Anti-EGFP phage RD1 5'-3'

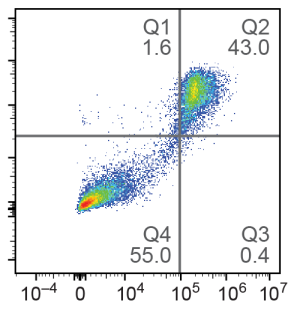

Anti-EGFP phage No RD1

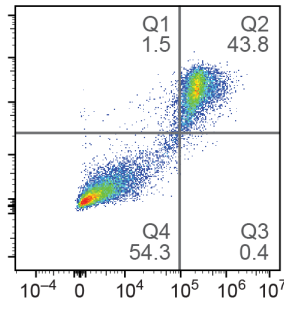

G

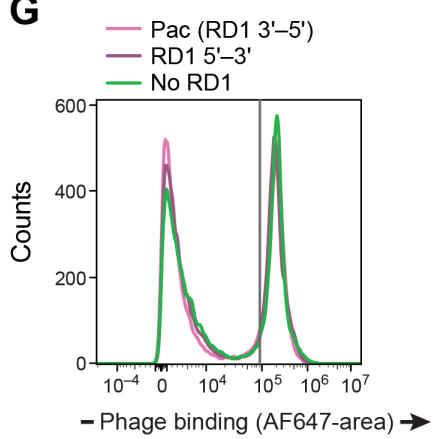


bioRxiv reprint dol: https://doi.org/10.1101/2020.10.01.322420; this version posted October 2, 2020. The copyright holder for this preprint
(which was not certified by peer review) is the author/funder, who has granted bioRxiv a license to display the preprint in perpetuity. It is made

(which was not certified by peer review) is the author/funder, who has granted bioRxiv a license to display the preprint in perpetuity. It is made
available under aCC-BY-NC-ND 4.0 International license.

Supp. Figure 5
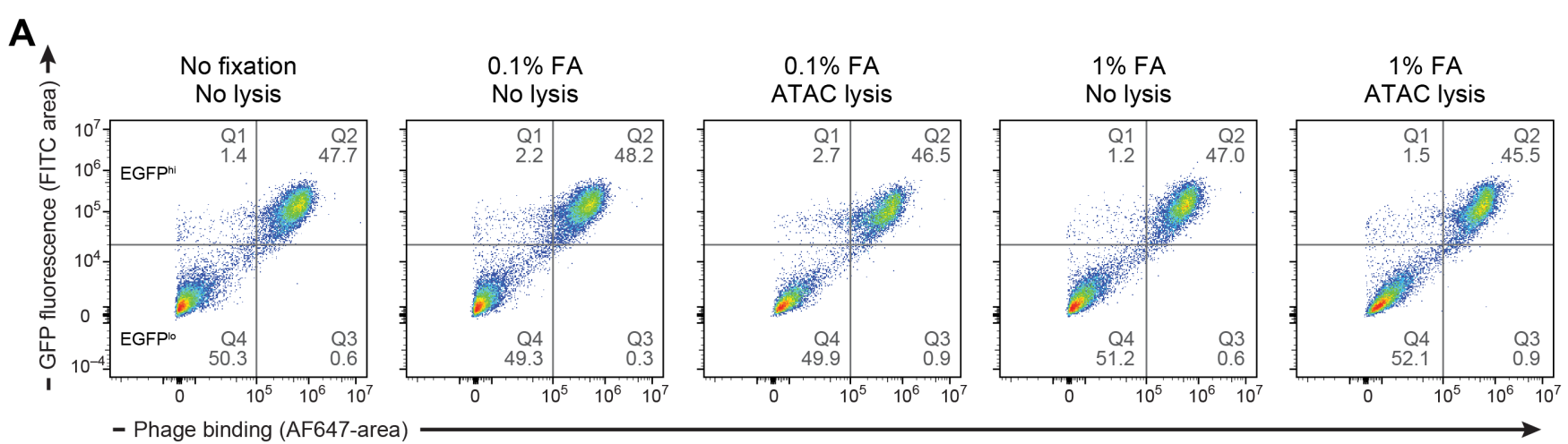

B

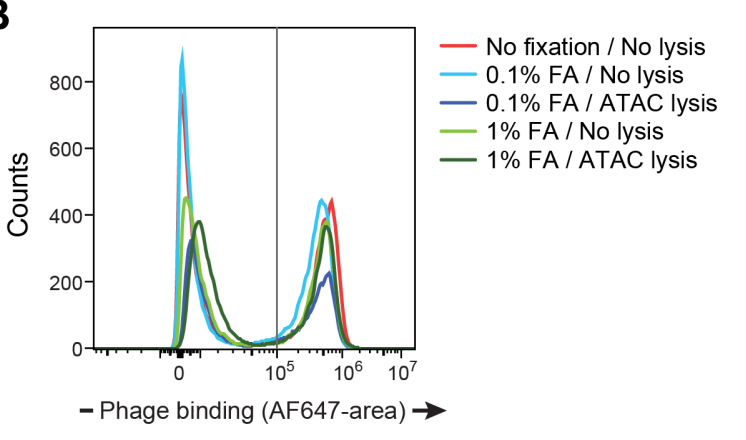


bioRxiv preprint doi: https://doi.org/10.1101/2020.10.01.322420; this version posted October 2, 2020. The copyright holder for this preprint (which was not certified by peer review) is the author/funder, who has granted bioRxiv a license to display the preprint in perpetuity. It is made available under aCC-BY-NC-ND 4.0 International license.

\section{Supp. Figure 6}

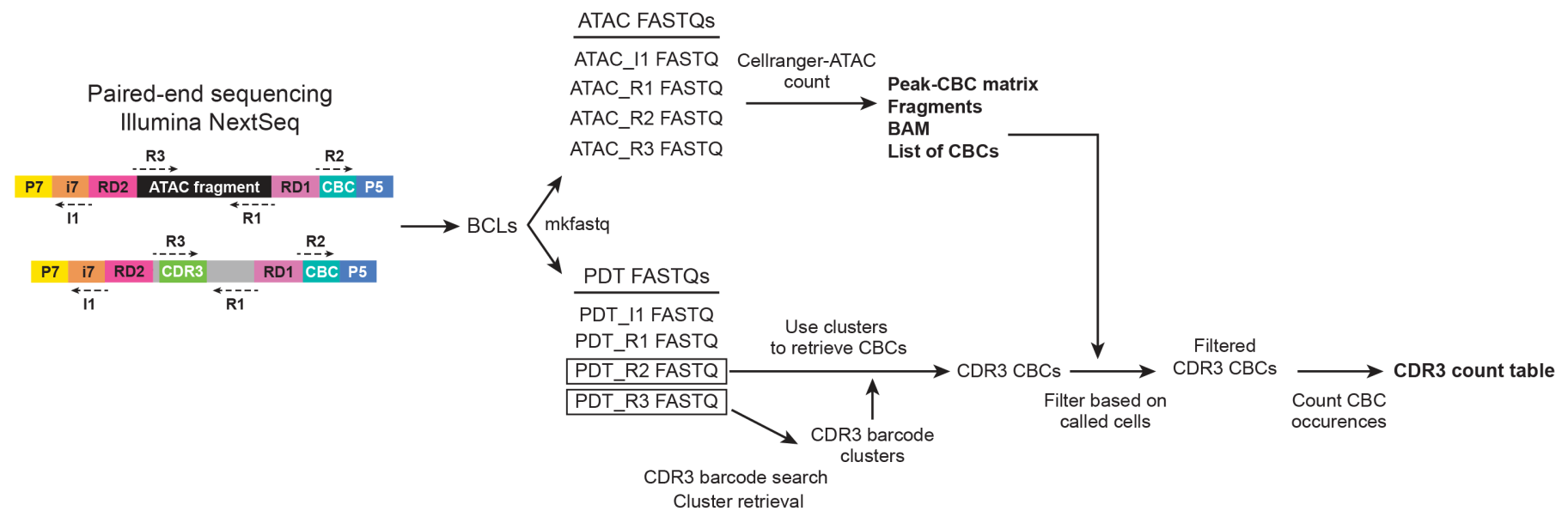




\section{Supp. Figure 7}

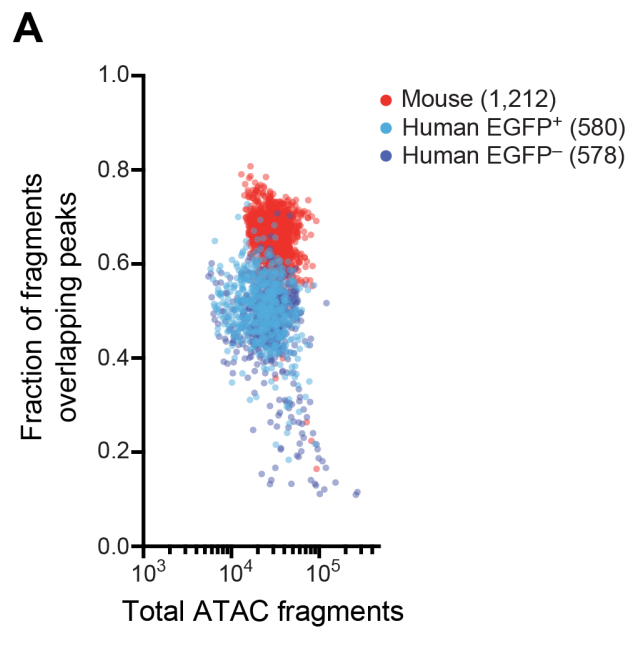

B

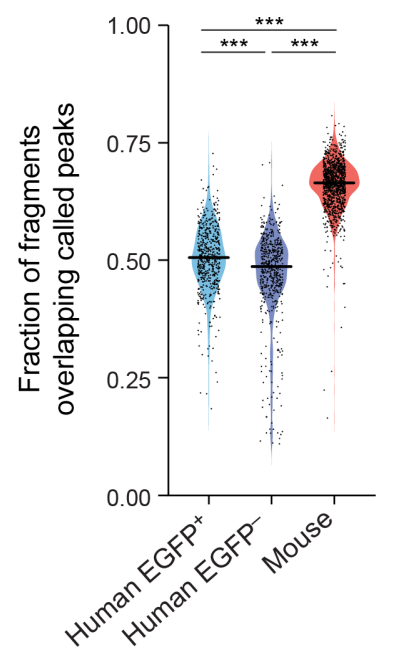

C

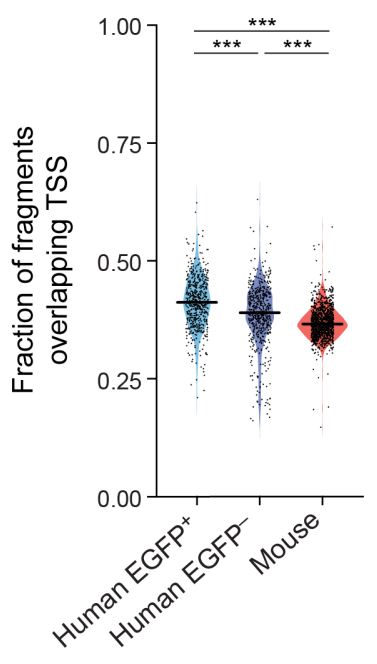




\section{Supp. Figure 8}

A

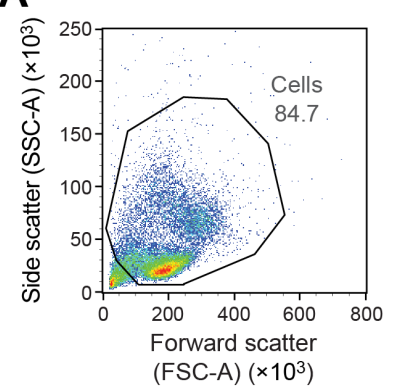

B Anti-EGFP phage

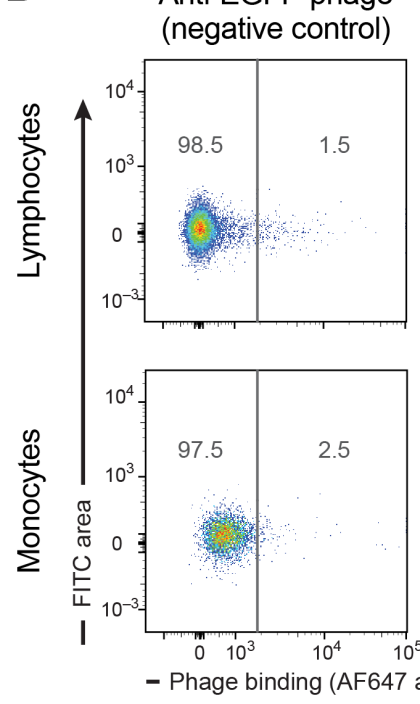

C

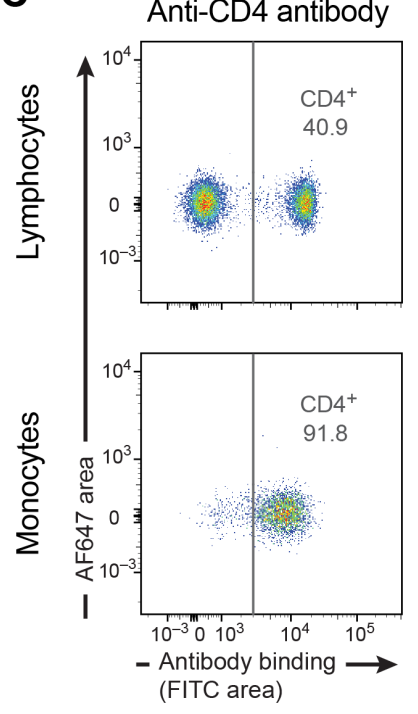

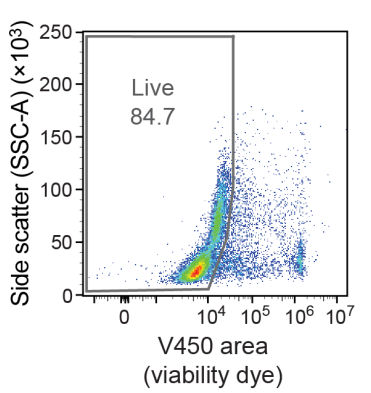
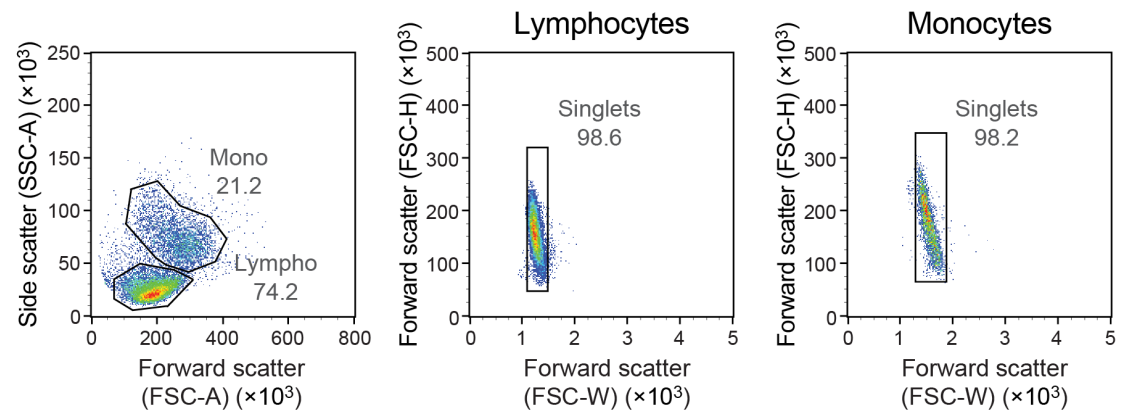

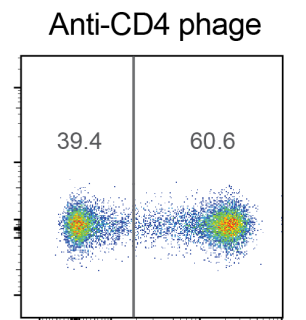

Anti-CD16 phage
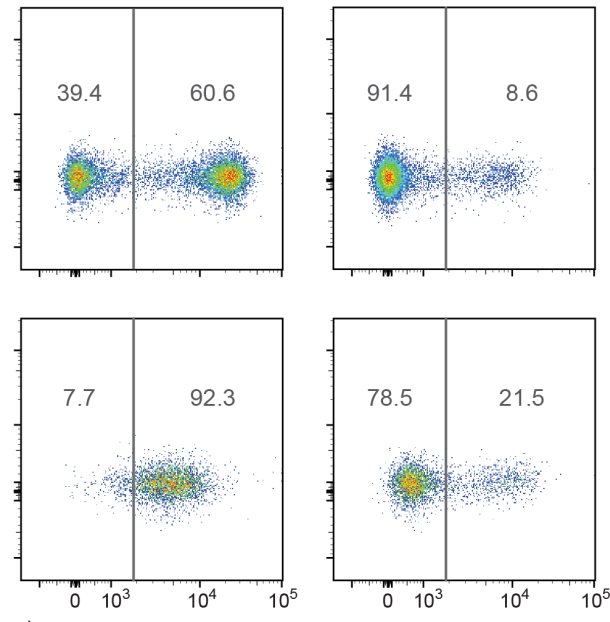

Anti-CD8 phage
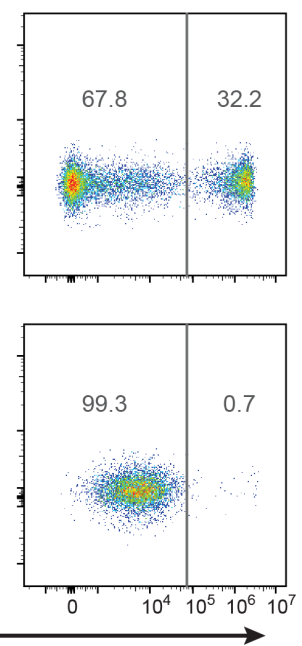

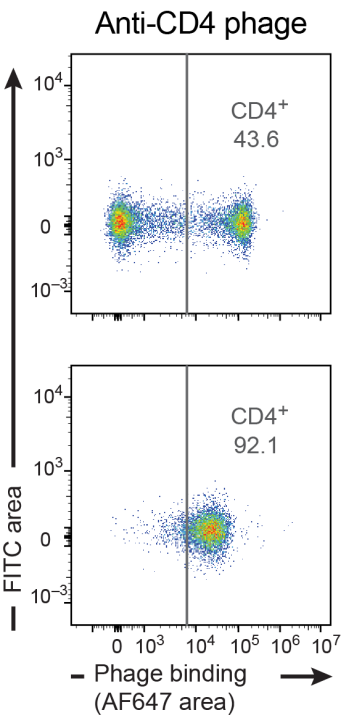




\section{Supp. Figure 9}

A
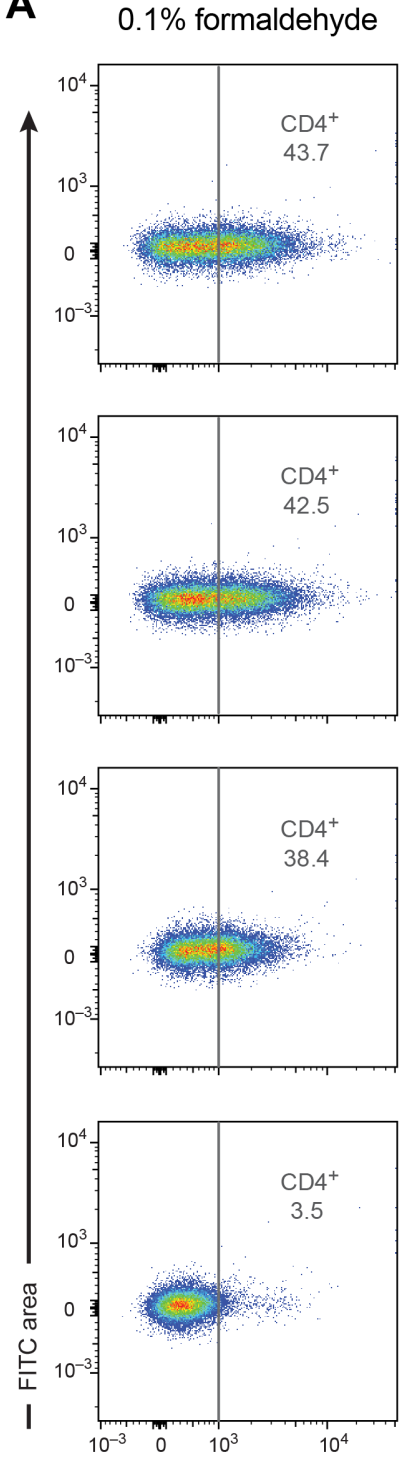

- Phage binding (AF647 area)

\section{B}

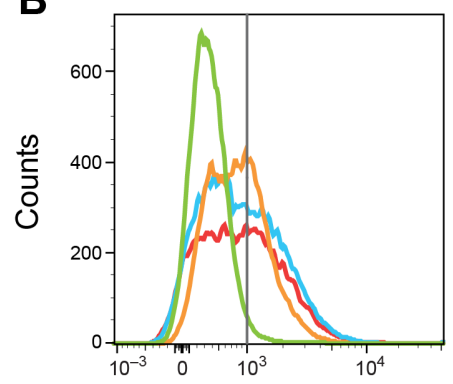

- Phage binding (AF647 area)
$1 \%$ formaldehyde
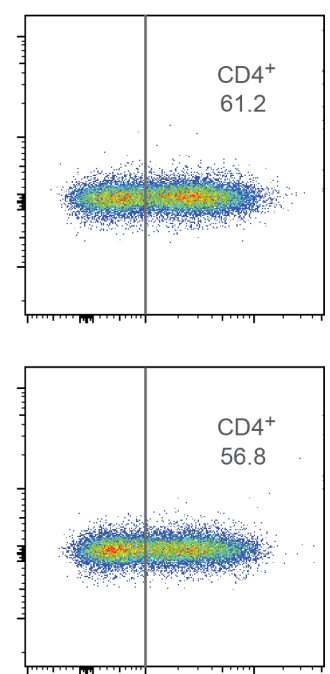

$0.1 \%$ NP-40

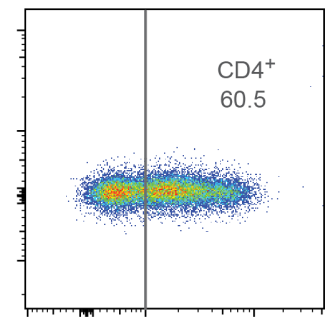

$0.01 \%$ Digitonin

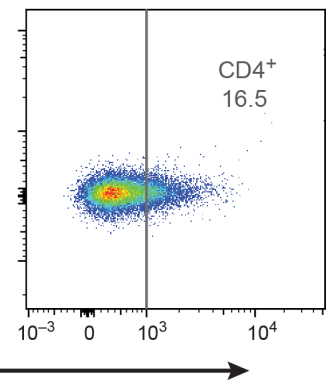

ATAC lysis buffer

(0.1\% Tween-20,

$0.1 \%$ NP-40,

$0.01 \%$ Digitonin)

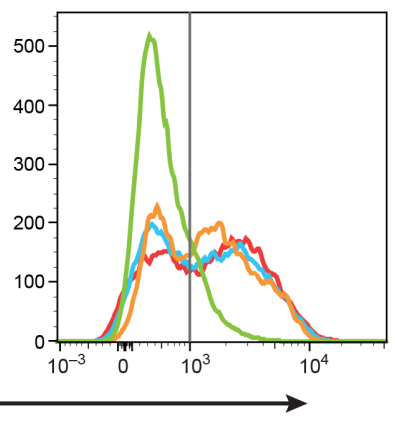

$$
\begin{aligned}
& \text { - No detergent } \\
& -0.1 \% \text { NP-40 } \\
& -0.01 \% \text { Digitonin } \\
& \text { - ATAC-lysis buffer } \\
& \text { (0.1\% Tween-20, } \\
& 0.1 \% \text { NP-40, } \\
& 0.01 \% \text { Digitonin) }
\end{aligned}
$$




\section{Supp. Figure 10}

A
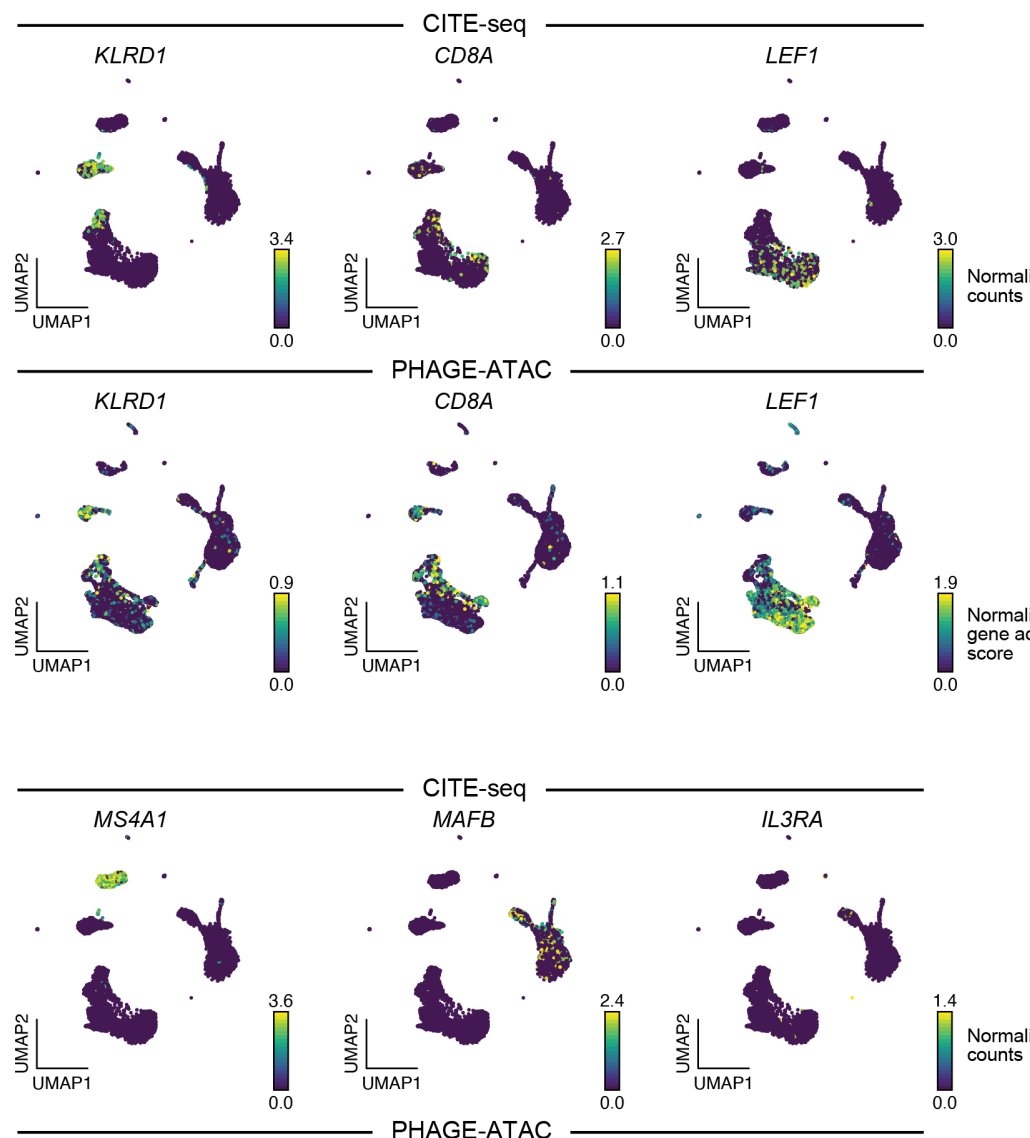

CITE-seq
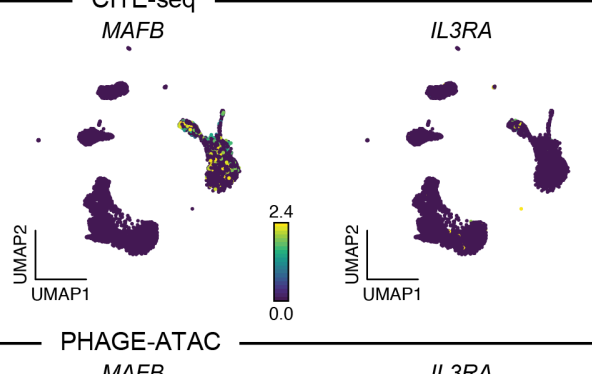

PHAGE-ATAC
MAFB
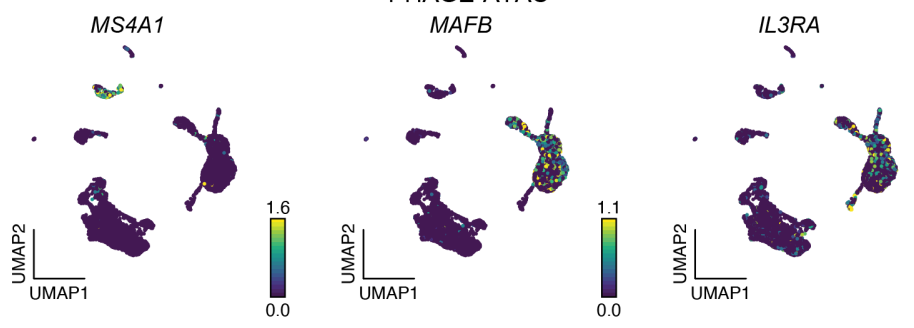

rmalized
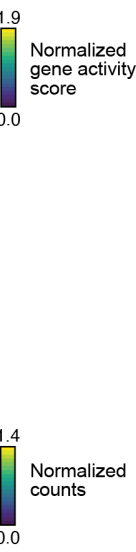

\section{B}

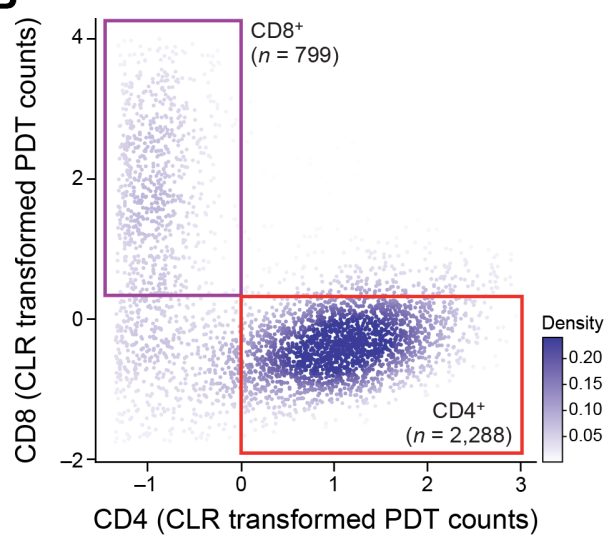

C

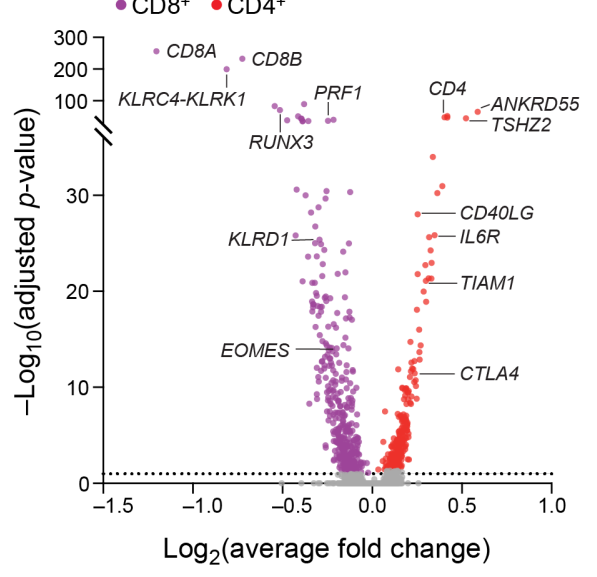

D

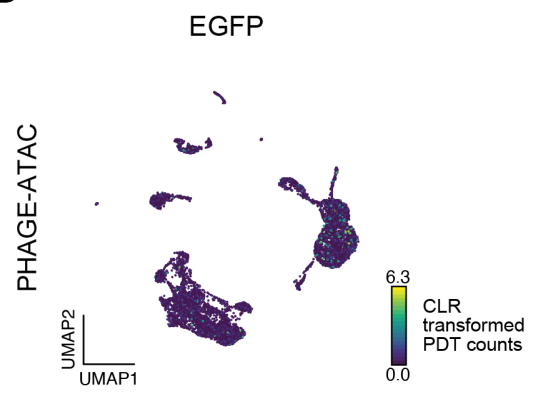

E

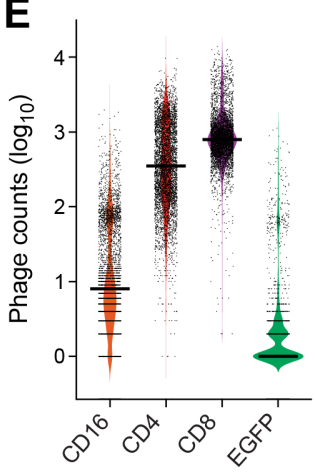


bioRxiv preprint doi: https://doi.org/10.1101/2020.10.01.322420; this version posted October 2, 2020. The copyright holder for this preprint (which was not certified by peer review) is the author/funder, who has granted bioRxiv a license to display the preprint in perpetuity. It is made available under aCC-BY-NC-ND 4.0 International license.

\section{Supp. Figure 11}

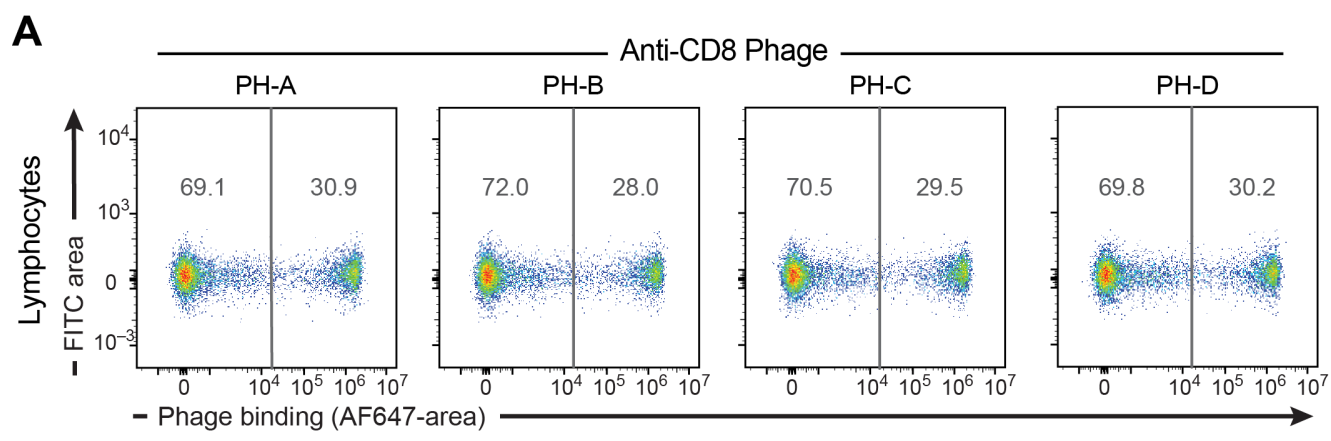

B

- Naïve CD8 T cell Effector CD8 T cell 3

- B cell 1

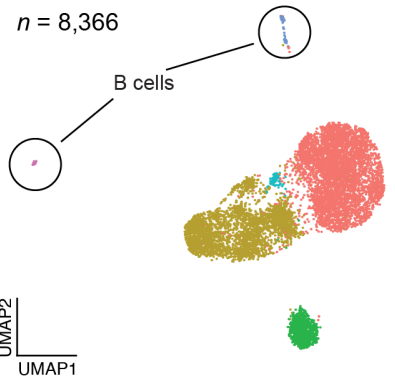

C $\begin{array}{ll}\text { - Naïve CD8 T cell } & \text { - Effector CD8 T cell } 3 \\ \text { - Effector CD8 T cell } 1 & \text { - B cell } 1 \\ \text { - Effector CD8 T cell } 2 & \text { - B cell } 2\end{array}$

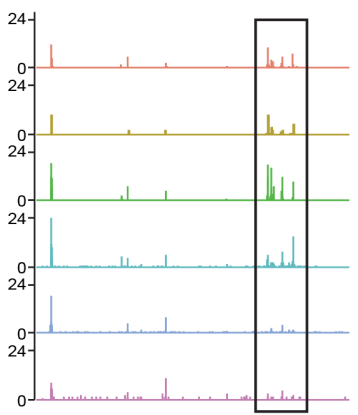

HHHW HW , H H H HWH KDM3A NM_001198954 CD8A CD8B

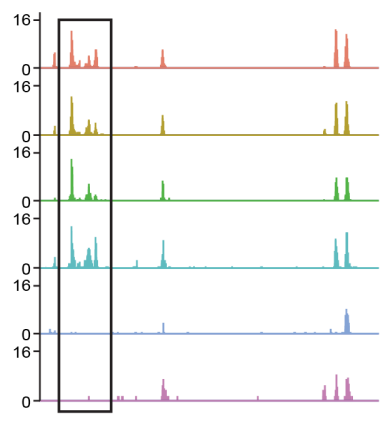

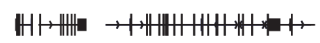

CD3D CD3G UBE4A NR_046369

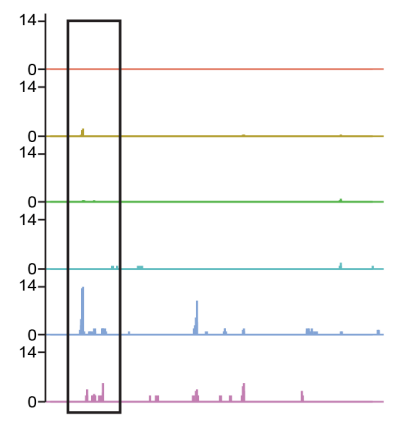

$\mapsto$ - WII-

$M S 4 A 1$

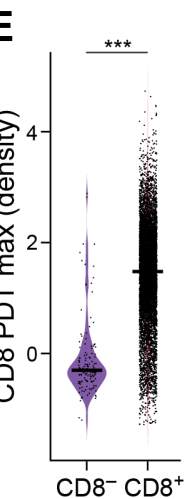

$\rightarrow$ 十⿻卄1|

F

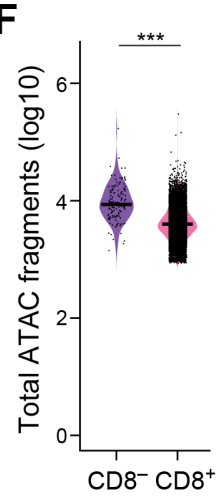

D

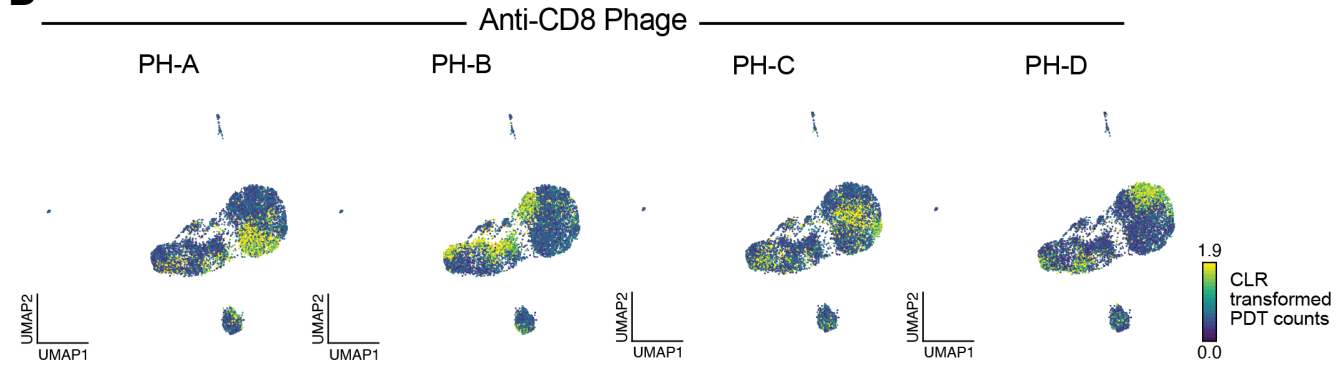

G

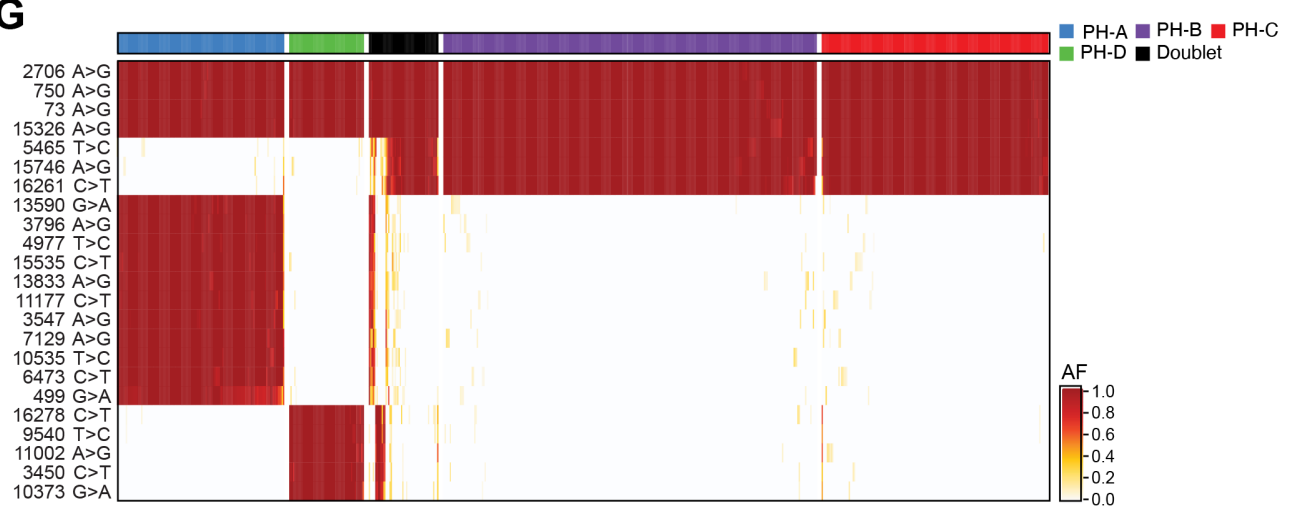


bioRxiv preprint doi: https://doi.org/10.1101/2020.10.01.322420; this version posted October 2, 2020. The copyright holder for this preprint (which was not certified by peer review) is the author/funder, who has granted bioRxiv a license to display the preprint in perpetuity. It is made available under aCC-BY-NC-ND 4.0 International license.

\section{Supp. Figure 12}

A

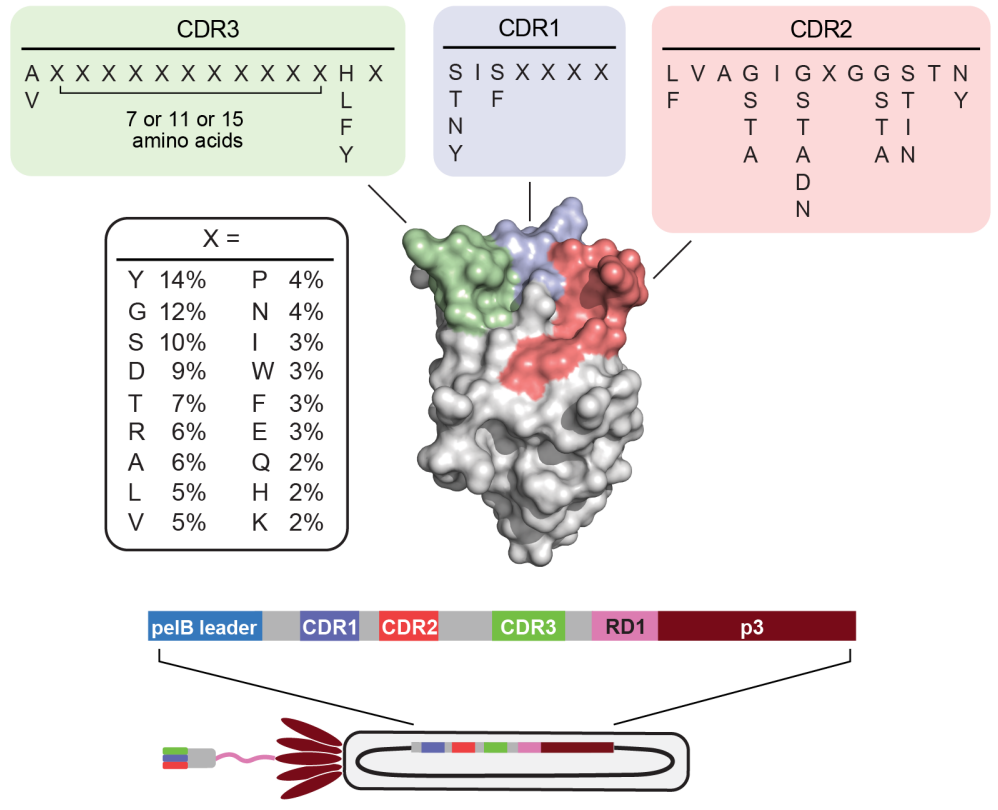

B

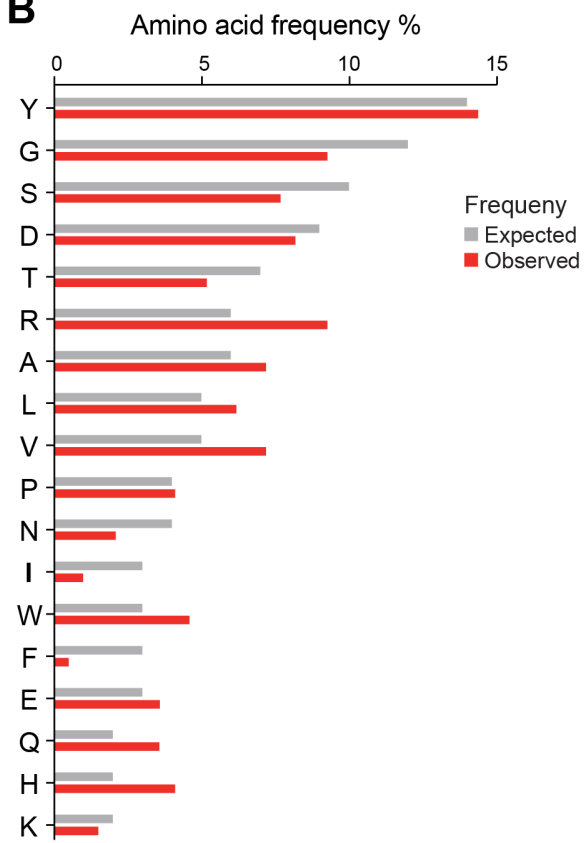

C Clone

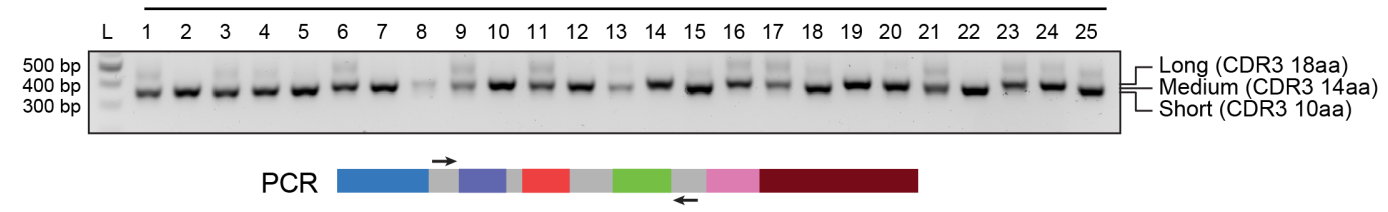

D

\begin{tabular}{|c|c|c|}
\hline Clone & CDR1 & CDR2 \\
\hline 4 & $N$ I F T Y G Y & $L V A T I D Y G T N T Y$ \\
\hline 7 & T I FWDEH & $F \vee A T I D D G G S T Y$ \\
\hline 8 & $S I F Q P \vee D$ & LVASIGWGGSTN \\
\hline 11 & $T$ I F V W L Y & $L \vee A T I T G G G S T N$ \\
\hline 12 & T I S Y K G D & $F \vee A S|N R G G| T N$ \\
\hline 14 & $N$ I F G N T D & $L \vee A G|G A G G| T N$ \\
\hline 16 & Y ISYYNS & $F \vee A T I D T G S \mid T Y$ \\
\hline 18 & Y I S VW Q G & LVAA ISYGGTTY \\
\hline 19 & $T \mid F Y G S Y$ & $F \vee A A \mid A E G G S T Y$ \\
\hline 20 & S I SPWYA & LVAG INGGGNTY \\
\hline 22 & S I SAWDV & $F \vee A T \mid T R G T N T Y$ \\
\hline \multirow[t]{2}{*}{24} & Y IS D R G T & $F \vee A A|G A G S| T Y$ \\
\hline & * & $* \quad * \quad * \quad * \quad *$ \\
\hline
\end{tabular}

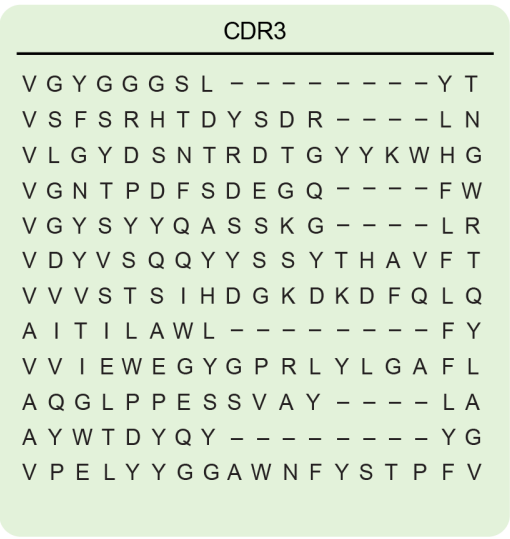

$\frac{\text { CDR3 length }}{\text { Short }}$

Medium

Long

Medium

Medium

Long

Long

Short

Long

Medium

Short

Long 
bioRxiv preprint doi: https://doi. org/10.1101/2020.10.01322420; this version posted October 2, 2020. The copyright holder for this preprint (which was not certified by peer review) is the author/funder, who has granted bioRxiv a license to display the preprint in perpetuity. It is made available under aCC-BY-NC-ND 4.0 International license.

\section{Supp. Figure 13}

A
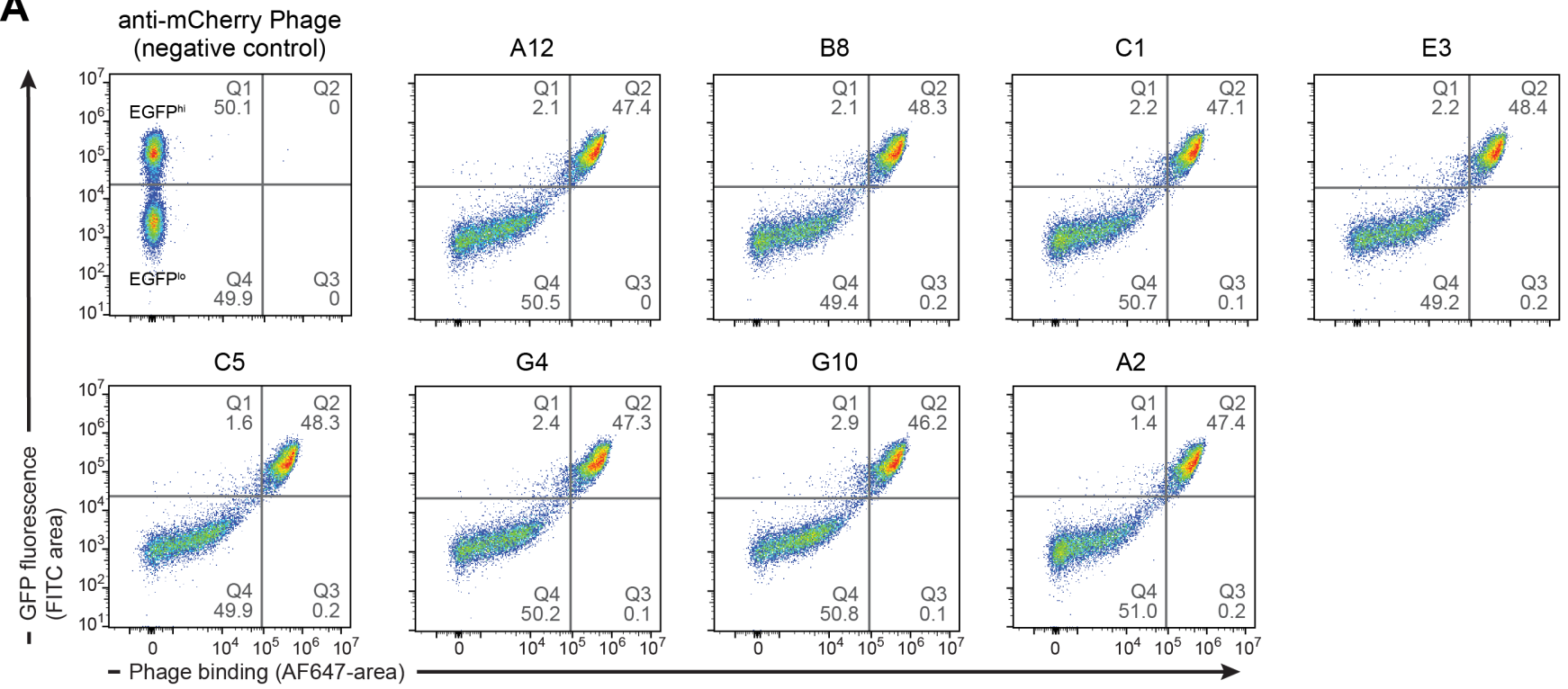

B
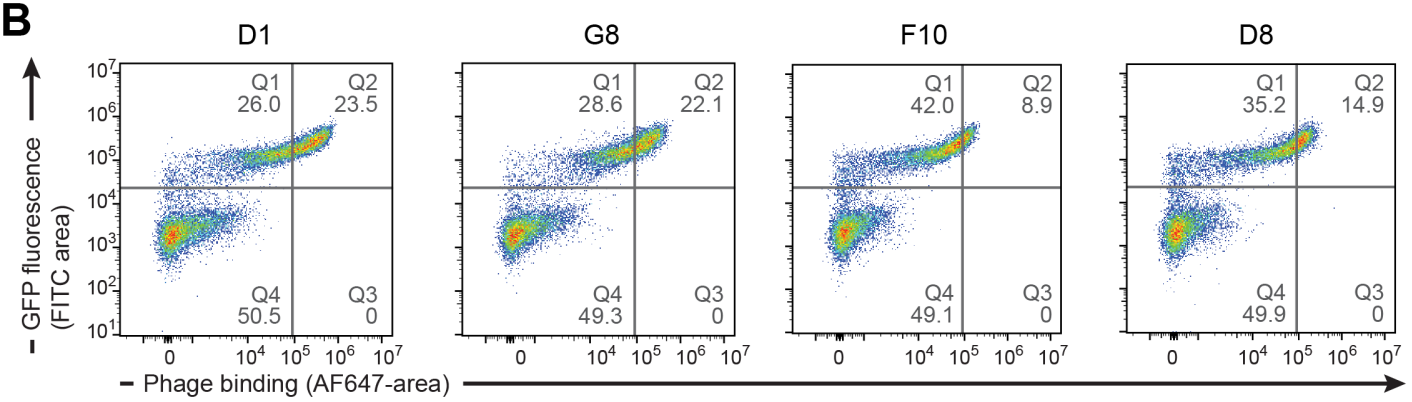


\section{Supp. Figure 14}

\section{PHAGE-ATAC}

\begin{tabular}{|l|c|}
\hline $\begin{array}{l}\text { Ordering Nb sequence } \\
\text { (IDT, } \sim 370 \text { bp) }\end{array}$ & $\sim 22.2 \$$ \\
\hline Phagemid cloning & $\sim 25 \$$ \\
\hline $\begin{array}{l}\text { Phage production } \\
\text { purification (10 rxns) }\end{array}$ & $\sim 25 \$$ \\
\hline $\begin{array}{l}\text { Barcoded phage } \\
\text { nanobodies 10 rxns }\end{array}$ & $\sim 72.2 \$$ \\
\hline Cost per rxn & $\sim 7.22 \$$ \\
\hline
\end{tabular}

One time cost

PHAGE-ATAC

\begin{tabular}{|l|c|}
\hline $\begin{array}{l}\text { Ordering Nb sequence } \\
\text { (IDT, } \sim 370 \mathrm{bp} \text { ) }\end{array}$ & $\sim 22.2 \$$ \\
\hline Phagemid cloning & $\sim 25 \$$ \\
\hline $\begin{array}{l}\text { Phage production } \\
\text { purification (100 rxns) }\end{array}$ & $\sim 250 \$$ \\
\hline $\begin{array}{l}\text { Barcoded phage } \\
\text { nanobodies } 100 \text { rxns }\end{array}$ & $\sim 297.2 \$$ \\
\hline Cost per rxn & $\sim 2.97 \$$ \\
\hline
\end{tabular}

